\title{
Beceri Temelli Bir Düşünme Programı Uygulamasının Sınıf Öğretmeni Adaylarının Eleştirel Düşünme Becerileri ve Eğilimlerine Etkisi*
}

\author{
Gülsüm ÇATALBAŞ*** Emel SARITAŞ****
}

- Geliş Tarihi: 16.07.2021 • Kabul Tarihi: 27.09.2021 • Çevrimiçi Yayın Tarihi: 28.07.2021

\section{$\ddot{\mathbf{O} z}$}

Bu araştırmanın amacı, CoRT 5 düşünme programının, sınıf öğretmeni adaylarının eleştirel düşünme beceri ve eğilimlerini nasıl etkilediğini araştırmaktır. Araştırma durum çalışması olarak desenlenmiştir. Araştırmanın çalışma grubunu oluşturan 21 sınıf öğretmeni adayına 10 haftalık CoRT 5 düşünme programı uygulanmıştır. Araştırmanın veri toplama araçları; katılımcı ve araştırmacı günlükleri, gözlem notları ve yarı-yapılandırılmış görüşmelerdir. Araştırmanın verileri tematik analiz yöntemi ile çözümlenmiştir. Yapılan analizler sonucunda; CoRT 5 düşünme programı uygulamasında karşılaşılan düşünme zorluklarında, düşünme zorluklarına bulunan çözümlerde ve CoRT 5 düşünme programının öğrenme çıktılarında eleştirel düşünmeye ilişkin göstergeler ortaya çıkmıştır. CoRT 5 düşünme programı uygulamasının sınıf öğretmeni adaylarının eleştirel düşünme becerilerini ve eğilimlerini geliştirmeye yönelik katkılar sağladığı görülmüştür. Sınıf öğretmeni adayları eleştirel düşünme eğitiminde daha çok beceri temelli yaklaşımın daha etkili olabileceğini belirtmiştir.

Anahtar sözcükler: eleştirel düşünme, beceri temelli eleştirel düşünme, CoRT düşünme programı, sinıf öğretmeni adayları

Atıf:

Çatalbaş, G. ve Sarıtaş, E. (2022). Beceri temelli bir düşünme programı uygulamasının sınıf öğretmeni adaylarının eleştirel düşünme becerileri ve eğilimlerine etkisi. Pamukkale Ĕgitim Fakültesi Dergisi, 54, 328-356.doi:10.9779.pauefd.972466.

\footnotetext{
* Bu makale birinci yazar tarafından ikinci yazar danışmanlığında tamamlanmış doktora tezinden üretilmiştir.

** Öğr. Gör.Dr., Pamukkale Üniversitesi, Eğitim Fakültesi, Eğitim Programları ve Öğretim Anabilim Dalı, Denizli, Türkiye, https://orcid.org/0000-0001-6971-1079, catalbas@pau.edu.tr

*** Dr. Öğr. Üyesi, Pamukkale Üniversitesi Eğitim Fakültesi, Sınıf Eğitimi Anabilim Dalı ,Denizli, Türkiye, https://orcid.org/0000-0000-0002-0101-4987, esaritas@pau.edu.tr
} 


\section{Giriş}

Bilim ve teknolojinin çok hızlı bir şekilde ilerlediği 21. yüzyılda toplumsal yapılarda değişim ve gelişim bireylerin bilgiye ulaşma ve düşünme biçimlerinin de değişimini zorunlu kılmıştır. Nitelikli bir toplum için bireylerin sistematik olarak düşünme yapılarını geliştirmeleri, düşünme becerilerinin farkına varmaları ve bunları kullanabilme becerilerine sahip olmaları gerekmektedir. Lipman (2003) düşünme becerilerini insanlığın en büyük zihinsel gücü olarak ifade ederken, bu becerileri sorgulama, akıl yürütme, bilgiyi düzenleme ve transfer becerileri olarak sınıflamıştır. Bireyin neyi bilmesi gerektiğinden daha çok nasıl bileceğini öğrenmesi için düşünme becerilerinin farkında olması gerektiğini belirten Mcguinness'e (2000) göre düşünme becerileri; bilgiyi elde etme ve anlamlandırma, eleştirel düşünme, yaratıcı düşünme, problem çözme, planlama ve karar verme becerilerinden oluşur. Fisher (1995) ise düşünme becerilerini, eleştirel düşünme, yaratıcı düşünme ve bu iki becerinin uygulaması olarak problem çözme becerisi şeklinde ayırmaktadır. 21. yüzyıl becerileri arasında öğrenme ve yenilikçilik becerileri altında eleştirel düşünme, yaratıcılık ve problem çözme alt beceriler olarak yer almıştır. (Larson, Miller, 2011; Trilling ve Fadel, 2009).

Düşünme becerileri ve bu becerilerin öğretim programlarındaki yeri incelendiğinde ortak olarak vurgulanan ve öne çıkaran beceri eleştirel düşünme becerisidir. Düşünme sürecinin ve bilgiye bakışın değişmesiyle bireylerin nasıl düşündüklerinin önem kazanması ve düşünmenin sadece niceliğini artırmaya değil aynı zamanda niteliğini de geliştirmeye çalışılması eleştirel düşünmeye odaklanılmasını sağlamaktadır (Fisher, 2001; Gündoğdu, 2009; ve Schafersman, 1991). Doğanay (2000), Facione (2013) ve Gürkaynak, Üstel ve Gürgöz' e (2008) göre demokratik toplumlardaki bireylerin taşıması gereken yeterliklerden biri olması eleştirel düşünmeyi önemli kılan nedenlerden biridir.

Eleştirel düşünme ile ilgili alan yazın incelendiğinde eleştirel düşünmenin tanımlarında, eleştirel düşünmenin boyutlarıyla ilgili sınıflamalarda ve eleştirel düşünmenin öğretimine ilişkin yaklaşımlarda farklılıkların olduğu görülmektedir. Bu farklılıkların nedeni her bir disiplinin kendi araştırma alanları doğrultusunda eleştirel düşünmeyi ele almalarıyla açıklanabilir. Felsefe perspektifinde, eleştirel düşünmenin doğasında ve sistematiğinde felsefi düşünme ve eleştirel düşünür özelliklerine odaklanılmıştır. Felsefe alanında eleştirel düşünme, "sorgulanmayan yaşam, yaşamaya değmez" (Gross, 2006, s.49) sözüyle sorgulamayı temel alan Sokrates'e kadar dayanmaktadır. Hem bir filozof, hem de bir psikolog olarak Dewey'in (1991)"bir inancın veya bilginin bu inanc1 ya da bilgiyi 
destekleyen kanıtlar ve ortaya koyduğu sonuçlar 1şığında aktif, dikkatli ve sürekli bir gözden geçirmeye, değerlendirmeye tabi tutulduğu bir düşünme"(s.6) olarak tanımladiğ derinlemesine düşünmede belirsizlik ve sorgulama olarak ifade ettiği iki temel süreç vardır. $\mathrm{Bu}$ süreç eleştirel düşünme kavramına vurgu yapmaktadır. "Çocuklar İçin Felsefe" nin kurucusu filozof Lipman (1988) eleştirel düşünmeyi ölçütlere dayalı, öz denetimli ve bağlama duyarlı bir süreç olarak tanımlamaktadır. Ennis (1985a) ise eleştirel düşünmeyi "ne yapılacağına veya neye inanılacağına dair karar vermeye odaklı yansıtıcı ve mantıklı bir düşünme" olarak tanımlamaktadır (s. 45).

Psikoloji disiplininde ele alınan eleştirel düşünme kavramında “düşünme nasıl gerçekleşir” sorusuyla daha çok süreç ele alınmıştır. Felsefe boyutu dışında eleştirel düşünmeyi psikolojik boyutta da ele alan Paul ve Elder (2013) düşünme üzerine düşünme olarak tanımlayarak bilişsel sürece dikkat çeker. Halpern (1998), Levy, (2010), Sternberg, (1985) ve Watson ve Glaser (2010) eleştirel düşünmeyi problem çözmeyle ilişkilendirmiştir. Cüceloğlu (1994) aktif ve organize bir süreç olarak eleştirel düşünmenin amacını "kendi düşünme süreçlerimizin bilincinde olarak, başkalarının görüşlerini göz önünde tutarak, öğrendiklerimizi uygulayarak, kendimizi ve çevremizdeki olayları anlayabilme" olarak açıklamaktadır (s. 216). Felsefe ve psikoloji disiplinlerinde farklı boyutlarıyla ele alınan eleştirel düşünme, eğitim bilimciler tarafından eğitim programlarının dört ögesi içinde ele alınarak incelenmiştir. Eleştirel düşünmenin niçin gerekli olduğu eğitim programının hedefler boyutunda ele alınırken, içerik ögesiyle çeşitli derslerde konuların içinde yer almaktadır. Öğrenme öğretme sürecinde eleştirel düşünmenin hangi yaklaşımlarla nasıl öğretileceği eğitimcilerin üzerinde çalıştıkları önemli bir alan olmuştur. Değerlendirme ögesinde ise eleştirel düşünmenin beceri ve eğilim bileşenlerine yönelik değerlendirme çalışmaları yapılmıştır.

Eleştirel düşünme tanımındaki farklılıklardan yola çıkan, farklı alanlarda uzman olan ABD ve Kanadalı 46 araştırmacı Delphi Araştırma Projesi kapsamında bir araya gelerek bu kavrama ilişkin fikir birliğine ulaşmaya çalışmışlardır. American Philosophical Association (APA) tarafından yürütülen bu çalışmada eleştirel düşünme; "yorumlama, analiz, değerlendirme ve çıkarımların yanında delillerin, kavramların, yöntemlerin, ölçütlerin ve bağlamların açıklanması ile amaca dayalı karar verme ve öz-denetimli bir şekilde yargıda bulunma" olarak tanımlanmıştır (Facione, 1990).

İyi bir eleştirel düşünür olabilmek için eleştirel düşünme becerileri ve eğilimleri bir bütün olarak ele alınmalıdır (Facione, 1990; Halpern, 2003; Watson ve Glaser, 2010). 
Eleştirel düşünme alanında farklılaşmalar eleştirel düşünmenin bu iki bileşenine yönelik sınıflamalarda da görülmektedir. Eleştirel düşünmede bilişsel boyutu ifade eden eleştirel düşünme becerileri Beyer, (1984), Ennis, (1985a), Paul, Binker, Martin, Vetrano ve Krelau (1989), Paul ve Elder (2013) ve Watson ve Glaser (2010) tarafindan sınıflandırılmıştır. Bu sınıflandırmalarda ortak olarak belirlenmiş beceriler dikkate alınarak Delphi projesi kapsamında eleştirel düşünme becerileri yönelik bir sınıflama yapılmıştır. Bu sınıflamada eleştirel düşünme becerileri; yorumlama, analiz, değerlendirme, çıkarımda bulunma, açıklama ve öz düzenleme becerileri ve alt beceriler şeklinde belirlenmiştir (Facione, 1990). Proje kapsamında bu sınıflama doğrultusunda bir ölçek de geliştirilmiştir.

Eleştirel düşünme eğilimlerini sınıflandıran araştırmacılar (Bailin, Case, Combs ve Daniels, 1999; Ennis, 1985b; Facione ve Facione, 1996; Fisher,1995; Halpern, 2003; Paul ve Elder, 2013) eleştirel düşünme becerisinin tek başına yeterli olmadığını, bu beceriyi kullanmaya yatkınlık ya da istekliliğin de olması gerektiğini vurgulamaktadır. Delphi projesinde eleştirel düşünme eğilimleri de sınıflandırılmıştır. Bu kapsamda eğilimler; yaşama yönelik eğilimler ve belirli konu, sorun ya da problemlere yönelik yaklaşımlar olarak sınıflandırılmıştır. Bu iki grupta toplanan özellikler, gerçeği arama, açık fikirlilik, analitiklik, sistematiklik, eleştirel düşünmede kendine güven, meraklı olma ve bilişsel olgunluk olmak üzere yedi kategoride toplanarak eleştirel düşünme eğilimlerini oluşturmuştur (Facione, 2013).

Eleştirel düşünmeye ilişkin bir tartışma alanı da eleştirel düşünme hangi yaklaşımlarla öğretimin daha etkili olduğu üzerinedir. Kennedy, Fisher ve Ennis (1991) eleştirel düşünme öğretiminde dört yaklaşımdan söz etmektedir. Bu yaklaşımlar; doğrudan yaklaşım, dolaylı yaklaşım, genel yaklaşım ve karma yaklaşım olarak sınıflandırılmıştır. Eleştirel düşünmenin konu temelli yani ders programları içerisinde yayılarak öğretilmesini savunan araştırmacılara (Halpern, 1998; Mcguinnes, 2000; McPeck, 1984; Nosich, 2015; Paul ve Elder, 2013; Resnick, 1987) göre eleştirel düşünme birkaç saatlik dersle öğretilemez. Konu içinde yayılarak bu becerilere yer verilmesi, derse karşı ilgi ve motivasyonun artmasını sağlar. Konu içine yayılarak verilmede doğrudan (infusion) ya da dolaylı yaklaşım (immersion) benimsenebilir. Doğrudan yaklaşımda, eleştirel düşünmenin genel ilkeleri daha önceden öğrencilere kavratılırken, dolaylı yaklaşımda genel ilkeler doğrudan verilmeyip konu alanı içine yayılarak eleştirel düşünme öğretimi gerçekleştirilir (Hager, Kaye, 1992; Mcguinness, 1999 ve Resnick, 1987;). Eleştirel düşünmenin beceri temelli öğretilmesi ya da genel yaklaşım olarak adlandırılan yaklaşımı benimseyen 
araştırmacılar (Beyer, 1985; De Bono, 2002; Ennis, 1985b; Fisher, 1995; Lipman, 1988 ve McCall, 2017) ise eleştirel düşünmenin ayrı bir ders ya da kurs aracılığıyla verilmesi gerektiğini savunmaktadırlar. Beceri temelli eleştirel düşünme öğretimi için Lipman’ in (2003) Çocuklar için Felsefe Programı, De Bono'nun (2002) Cognitive Research Trust (CoRT) Programı ve Feurstein'in Aracılı Zenginleştirme Programı gibi özel hazırlanmış programlar kullanılmaktadır. Son yaklaşım ise beceri temelli bir yaklaşımın doğrudan veya dolaylı yaklaşımlarla birleşmesinden oluşmuş karma yaklaşımdır (Kennedy, Fisher ve Ennis, 1991). Karma yaklaşımın bu üç yaklaşımın yetersizliklerini tamamlamaya yönelik bir yaklaşımdır.

Eleştirel düşünmenin hangi yolla ya da yaklaşımla öğretileceği tartışma konusu olabilir. Ancak bu becerinin kazandırılmasında önemli görevin öğretmenlere düştüğü tartışmasız bir konudur (Demirel, 2007; İdol, Jones ve Mayer, 1991; Narin ve Aybek, 2010; Seferoğlu ve Akbıyık, 2006). Etkili Öğretmenler ve Öğretim Komisyonu, öğrencilerin küresel zorluklarla baş edebilmesinde eleştirel düşünme, problem çözme ve yaratıc1 düşünme gibi 21. yüzyıl becerilerine sahip olarak yetişmelerinin gerektiğini ve bunun içinde öğretmenlerin ve öğretmen adaylarının bu becerilere sahip olmalarının önemini vurgulamıştır (Commission of Effective Teachers and Teaching [CETT], 2011).

Milli Eğitim Bakanlığı tarafından 2005 yılında yapılandırmacı yaklaşımın temel alındığ1 ilköğretim programında öğrencilere kazandırılacak ortak beceriler; eleştirel düşünme, yaratıcı düşünme, iletişim, araştırma-sorgulama, problem çözme, bilgi teknolojilerini kullanma, girişimcilik ve Türkçeyi doğru, etkili ve güzel kullanma becerileri olarak sıralanmıştır. Öğrencilerin "kuşku temelli sorgulayıcı bir yaklaşımla konulara bakma, yorum yapma ve karar verme becerisi” (MEB, Tebliğler Dergisi, 2004, 734) olarak ifade edilen eleştirel düşünme becerilerine sahip olmaları için onlara bu ortamı sağlayacak öğretmenlerin hizmet öncesinde yetiştirilmesi gerekir. Öğretmen adaylarıyla eleştirel düşünmenin beceri ya da eğilim boyutuna yönelik çalışmalar (Aybek, 2006; Çetinkaya, 2011; Doğanay, Taş ve Erden, 2007; Karsantık, 2016; Kartal, 2012; Korkmaz, 2009; Kürüm, 2002; Özden, 2005; Saçlı, 2013; Schreglman, 2011 ve Tok, 2008) bulunmaktadır. İlkokulun öğrencinin gelişimi açısından önemli bir yeri olduğu göz önünde bulundurulduğunda, öğretmenlerinin hizmet öncesinde yetiştirilmesi gerekliği dikkate alınarak bu araştırma sınıf öğretmenliği adayları ile gerçekleştirilmiştir. Bu noktada hizmet öncesi eğitimde eleştirel düşünme en etkili şekilde nasıl kazandırılabilir sorusu önem kazanmaktadır. Araştırmanın gerçekleştiği 2016-2017 öğretim yılında öğretmen yetiştirme 
programında düşünme becerilerine yönelik bağımsız bir ders bulunmamaktadır. Araştırmacı eleştirel düşünmenin beceri temelli bir ders ve buna yönelik programlarla daha etkili öğretilebilir mi sorusundan yola çıkmıştır.

Eleştirel düşünmenin beceri temelli derslerle öğretimine yönelik programlar içinde Edward De Bono tarafından oluşturulmuş CoRT Düşünme programı, sistematik bir şekilde düşünmenin doğrudan öğretimine yönelik düşünme araçlarından oluşmuş bir programdır. De Bono'nun (2002) altı yaş grubundan yetişkinlere kadar her yaş grubunda ve farklı alanlarda rahatlıkla uygulanabilecek etkinlikleri içerdiğini belirttiği program altı bölümden ve her bölümde 10 dersten oluşmaktadır. CoRT düşünme programı Amerika, İngiltere, İrlanda, Kanada, Avustralya, Malta, Yeni Zelanda, İtalya, Venezüela, Malezya, Singapur ve Güney Afrika gibi birçok ülkede yoğun bir şekilde uygulanmakta olup, eğitim programlarında yer almaktadır. Bu programın uygulandığı araştırmalar (Ritchie ve Edwards, 1996, Barak ve Doppelt, 2006; Aybek, 2006; Al-Edwan, 2011; Rule ve Stefanick, 2012) programın farklı alanlarda etkili bir şekilde kullanılabileceğini gösterirken, Türkiye'de yapılan araştırmalar (Aybek, 2006; Bayrak, 2014; Korkmaz ve Keleş, 2014) CoRT 1 uygulamalarıyla sınırlıdır. Beşinci bölüm olan Bilgiler ve Duygu (CoRT 5); bilgi, sorular, ipuçları, çelişkiler, tahminler, inançlar, fikirler, duygular, değerler ve basitleştirme başlıklı dersler altında, düşünme etkinlikleri, çözüm yolları ile ilgili yordamaların yapıldığı bir bölümdür. Bundan dolayı bu araştırmada eleştirel düşünme becerilerini geliştirmeye yardımcı olabileceği düşünülen CoRT 5 programı kullanılmıştır.

Araştırmanın amacı CoRT 5 düşünme programının öğretmen adaylarının eleştirel düşünme beceri ve eğilimlerini nasıl etkilediğini araştırmaktır. $\mathrm{Bu}$ amaç doğrultusunda; “CoRT 5 düşünme programı eğitimi alan sınıf öğretmeni adaylarında eleştirel düşünmeye ilişkin göstergeler nelerdir”, “CoRT 5 düşünme programı eğitimi, sınıf öğretmeni adaylarının eleştirel düşünme beceri ve eğilimlerine ne tür katkılar sağlamıştır?” ve Sınıf öğretmeni adaylarının eleştirel düşünme eğitimine yönelik görüşleri nelerdir? sorularına yanıt aranmıştır.

\section{Yöntem}

\section{Araştırmanın Deseni}

$\mathrm{Bu}$ araştırmada nitel araştırma desenlerinden bütüncül tek durum çalışması kullanılmıştır. Meriam' a (2013) göre durum çalışmasının amacı, hipotezi test etmek yerine duruma yoğunlaşarak o olguya ilişsin önemli faktörlerin etkileşiminin ortaya çıkarılmasıdır. 
Araştırmada bütüncül tek durum desenini tercih etmede; öğretmen adaylarına düşünme programı uygulamasının, eleştirel düşünme beceri ve eğilimlerini nasıl etkilediği, incelenen durum olarak belirlenmiş ve bu programın eleştirel düşünme beceri ve eğilimlerine katkı sağlaması doğrulanmaya ya da çürütülmeye çalışılması belirleyici olmuştur. Ayrıca Türkçe alan yazında öğretmen adaylarıyla gerçekleştirilen CoRT 5 düşünme programı uygulamasına yönelik çalışmaların olmaması kendine özgü bir durum olarak değerlendirilmiştir.

\section{Katılımcılar}

$\mathrm{Bu}$ araştırmanın katılımcıları, amaçlı örneklem türlerinden ölçüt örnekleme ile belirlenen Eğitim Fakültesinde öğrenim gören, dördüncü sınıf 21 sınıf öğretmeni adayıdır. Katılımcıların belirlenmesinde Öğretmenlik Uygulaması I dersini alıyor olmaları ve daha önce bir düşünme eğitimi programına katılmamış olmaları dikkate alınmıştır. Katılımcılar 16 kadın, beş erkek sınıf öğretmeni adayından oluşmaktadır. Ağırlıklı olarak genel lise ve anadolu lisesi mezunları olan katılımcıların 15'i öğretmenlik mesleğini isteyerek, altısı ise istemeden seçmiştir. Üniversite girişte bölüm tercih sıralamasında ilk altı tercihte bulunanlar çoğunluktadır. Katılımcıların 14'ü kendilerini eleştirel düşünür olarak orta düzeyde, ikisi iyi düzeyde, beş öğretmen adayı ise zayıf düzeyde bulmaktadır. Katılımcıların çoğunluğu güncel bilgilere ulaşmada bilgi kaynağı olarak en çok interneti ve sosyal medyayı kullanmaktadir.

\section{Veri Toplama Araçları}

Araştırmada birden fazla nitel veri toplama tekniği kullanılarak veri çeşitlemesine gidilmiştir. Böylece toplanan verilerin birbirini doğrulaması sağlanarak araştırmada inanırlık artırılmaya çalışılmıştır (Merriam, 2013). Bu çerçevede araştırmanın veri toplama araçları, “Kişisel Bilgi Formu”, “Katılımcı Günlükleri”, “Araştırmacı Günlüğü”, “Katılımcı Gözleme İlişkin Video Kayıtları” ve "Yarı-yapılandırılmış Görüşmeler” olarak belirlenmiştir.

\section{Kişisel bilgi formu}

Kişisel bilgi formu katılımcıları daha iyi betimleyebilmek için ve gerektiğinde bulguları yorumlamak amaciyla oluşturulmuştur. Formda, cinsiyet, mezun olunan lise türü, sınıf öğretmenliğini seçmedeki istek durumları, üniversite sınavındaki tercih sırası, akademik ortalama, daha önce düşünme eğitimi dersi ya da kursu alıp almamaları ve eleştirel düşünür olarak kendilerini hangi düzeyde buldukları, güncel bilgilere ulaşmada hangi bilgi kaynaklarını kullandıkları ve kullanma sıklıklarına yönelik sorular yer almaktadır. 


\section{Katılımcı günlükleri}

Araştırmada uygulama boyunca her ders bitiminde, öğretmen adaylarının o günkü düşünme programı uygulamasına ilişkin ne yaptıklarını düşünmeleri ve görüşlerini günlük tutarak yazmaları istenmiştir. Katılımcı günlükleri için nitel araştırma deneyimi olan ve düşünme becerileri üzerine çalışmış iki uzmandan görüş alınarak sorular biçimde bir form oluşturulmuştur. Bu formda düşünme etkinliklerinde karşılaştıkları zorluklar, çözüm yolları, neler öğrendikleri ve öğrendiklerini günlük hayatlarında nasıl uygulayabilecekleri üzerine düşünmelerini sağlayan sorular yer almıştır.

\section{Araştırmacı günlüğ̈̈}

Araştırmacı programın uygulayıcısı olarak katılımcılarla etkileşime girmiş aynı zamanda bu durumu gözlemleyerek notlar almış ve yaşadığı deneyimleri günlüklerinde yansıtmıştır.

\section{Katılımcı gözlem}

Araştırmada gözlem türü olarak, katılımcı gözlem benimsenmiştir. Yin'in (2003) araştırmacının pasif bir gözlemci olmadığı özel bir gözlem modu olarak tanımladığı katılımcı gözlemi Merriam (2013), araştırmacının katılımcı rolüyle genellikle katıldı̆̆ 1 ancak faaliyetlere tamamen kendini vermediği bir gözlem türü olarak açıklamıştır. Bu araştırmada araştırmacı, katılımcı olarak gözlemci rolünü üstlenmiştir. Araştırmada katılımcı gözlem ile toplanan verilerin geçerliliğini artırmak amacıyla kamera ile video kayıtları alınmıştır.

\section{Yarı-yapılandırılmış görüşmeler}

Araştırmada düşünme programı uygulamasının bitiminde iki haftalık süreçte yarıyapılandırılmış görüşme formu kullanılarak bireysel görüşmeler yapılmıştır. Hazırlanan görüşme formuna nitel araştırma ve düşünme becerileri eğitiminde uzman iki öğretim üyesinden görüş alınarak son biçimi verilmiştir. Katılımcılara almış oldukları eğitimin eleştirel olarak nasıl düşündürdüğü, düşünme etkinlikleri esnasında geliştirdikleri stratejiler, düşünme yapılarında farklılık oluşturup oluşturmadığı ve eleştirel düşünmeye yönelik önerilerinin neler olduğu sorulmuştur. Görüşmeler katılımcılardan izin alınarak ses kayıt cihazı ile kaydedilmiştir.

\section{Uygulama ve Veri Toplama Süreci}

Bu araştırmada öncelikle temin edilen CoRT 5 düşünme programı İngilizce'den Türkçe'ye çevrilip, bir İngilizce uzmanının ve düşünme becerileri üzerine çalışmaları olan bir öğretim üyesinin görüşüne sunulmuştur. Alınan geri bildirimler doğrultusunda dil ve anlam bakımından gerekli düzeltmeler yapılmıştır. 
Uygulama, pilot ve asıl uygulama olarak iki aşamada gerçekleşmiştir. Pilot uygulama ile CoRT 5 düşünme programının anlaşılırlığını test edildikten sonra asıl uygulama 2016 2017 öğretim yılı güz yarıyılında öğrenim gören dördüncü sınıf öğretmen adaylarıyla Öğretmenlik Uygulaması I dersinde gerçekleştirilmiştir. Araştırmanın yapıldığı dönemde uygulamanın beceri temelli düşünme eğitiminde savunulan temel anlayışa uygun olarak bağımsız bir derste gerçekleşmesinin mümkün olmaması araştırmanın sınırlılığı olarak belirtilmiştir. Katılımcılara ilkokullarda eleştirel düşünme becerilerini gözlemlemeleri ve kendi eleştirel düşünme becerilerini değerlendirmelerine imkan veren ve bir öğretmen olarak düşünme firsatı sağlaması açısından düşünme programı uygulaması Öğretmenlik Uygulaması I dersinin iki saatlik teorik kısmında gerçekleştirilmiştir. Araştırma 14 hafta sürmüştür.

Uygulamanın ilk haftasında araştırmanın amacı ve süreci anlatılmıştır. Daha sonra on haftalık program uygulaması gerçekleştirilmiştir. Programın ilk dersi Bilgi dersi olup verilen bir durumla ilgili açık olarak bilinen bilgiler ve eksik olan bilgiler belirlenerek durum netleştirme çalışmaları yapılmıştır. . İkinci ders sorular dersidir. Balıkçı ve avcı sorularla bilgiyi elde etmek için soru sormanın önemine dikkat çekilmiştir. İpuçları dersinin olduğu üçüncü derste bilgiye ulaşmada, problemleri çözmede önemli parçalar olarak ipuçlarını bulma etkinlikleri yapılmıştır. Dördüncü derste çelişkiler ve hatalı sonuçların ayrımı yapılırken beşinci derste tahmin çalışmaları yapılmıştır. Altıncı ders inançlar dersidir. Bu derste kişinin sahip olduğu inançların kendi kişisel inançları mı yoksa başkalarının oluşturduğu inançlar mı olduğuna ilişkin düşünme çalışmaları yapılmıştır. İnançlar dersini takip eden fikirler dersinde de fikirlerin kaynağı incelenmiştir. Duyguların düşünmedeki önemine dikkat çekmeyi amaçlayan duygular dersinde sıradan ve egosal duygular üzerine düşünme etkinlikleri gerçekleştirilmiştir. Dokuzuncu ders değerlerin düşünme sürecindeki rolü, öğrencilerin değerlerin farkına varmasını amaçlayan bir desttir. Son ders karmaşık olarak görülen bilgileri daha basit ve net hale getirmeye yönelik etkinliklerinin yer aldığı basitleştirme dersi olarak gerçekleştirilmiştir. Uygulama sürecinde gözlem kayıtları, günlükler ile veriler toplanmıştır. 12. Haftada yarı yapılandırılmış görüşme takvimi belirlenip son iki haftada da bu görüşmeler gerçekleştirilmiştir.

\section{Verilerin Analizi}

$\mathrm{Bu}$ araştırmada verilerin analizinde tematik analiz kullanılmıştır. Braun ve Clarke' a (2006) göre tematik analiz, "verilerin içinde temaları belirleyen, analiz eden ve raporlayan analitik bir nitel araştırma yöntemidir (s.79). Altı aşamada gerçekleşen tematik analiz Şekil 1. de 

gösterilmiştir.
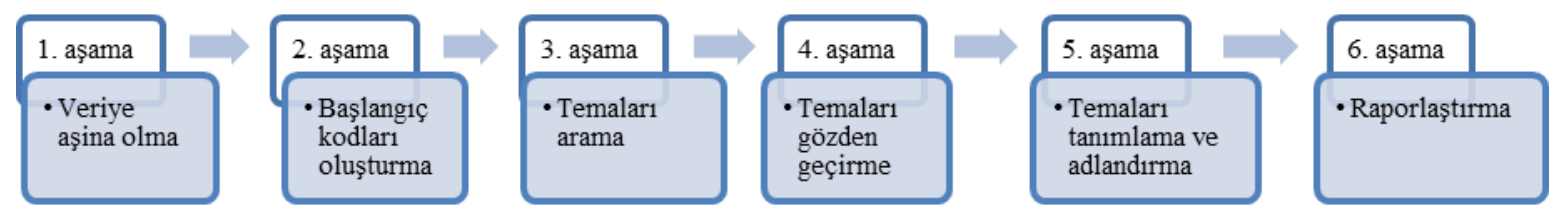

\section{Şekil 1. Tematik analizin aşamaları}

Verilerin analizinin ilk aşamasına araştırmacı günlüğünde "verilerle tanışma" demiştir. Bilgisayar ortamında metne dökülmüş verilerin ilk okumasını yapıldıktan sonra tekrar tekrar okuyarak ve verilerin ne anlatmak istediği üzerine düşünülmüş yani verilere aşina olunmaya çalışılmıştır. Tüm veri setinin sistematik olarak gözden geçirildiği, öne çıkan özelliklere göre kodlandığı ikinci aşamada okumaların sonunda verilerden benzer olanları bir kategori altında toplanmış ve kodlanmıştır. Üçüncü aşamada verilerden elde edilen kodlar ortak özellikler doğrultusunda bir tema altında toplanmıştır. Temaların gözden geçirildiği dördüncü aşamada belirlenmiş olan temalar ve o temalara ilişkin veriler tekrar tekrar okunarak gözden geçirilmiş ve farklı temalar olarak belirlenen temalar birleştirilmiştir. Daha sonra temaları alan yazın ve katılımcıların söylemleri doğrultusunda tanımlama ve adlandırma aşamasına geçilmiştir. Veri analizinin son aşamasında veri örneklerinden alıntılar yapılarak bulgular yorumlanmış ve alan yazın ile desteklenerek tartışılmış ve raporlaştırılmıştır.

\section{Bulgular}

Araştırma sorularına yanıt bulmak amacıyla yapılan nitel verilerin analizinden beş ana temaya ulaşılmıştır. Bu temalar CoRT 5 düşünme programı uygulamasında karşılaşılan düşünme zorlukları, düşünme zorluklarına bulunan çözümler, CoRT 5 düşünme programının öğrenme çıktıları, CoRT 5 düşünme programının eleştirel düşünme beceri ve eğilimlerine katkıları ve eleştirel düşünme eğitimine yönelik görüşler olarak belirlenmiştir. $\mathrm{Bu}$ ana temalara ilişkin bulgular ele alınırken araştırmanın odak noktasını oluşturan eleştirel düşünmeye ilişkin temalar ise beceri ve eğilimlere işaret eden alt temalar ile birlikte doğrudan alıntılar yapılarak sunulmuştur.

\section{CoRT 5 Düşünme Programında Eleștirel Düşünme Göstergeleri}

Araştırmanın birinci sorusu olan beceri temelli düşünme programı eğitimi alan sınıf öğretmeni adaylarında eleştirel düşünmeye ilişskin ortaya çıkan göstergelerin neler olduğuna yanıt aramak amacıyla veriler analiz edilmiştir. Bu analiz sonucunda "CoRT 5 düşünme programı uygulamasında karşılaşılan düşünme zorlukları”, “Düşünme zorluklarına bulunan 
çözümler” ve "CoRT 5 düşünme programının öğrenme çıktıları" ana temalarına ulaşılarak eleştirel düşünme göstergeleri incelenmiştir.

\section{CoRT 5 düşünme programı uygulamasında karşılaşılan düşünme zorlukları}

Araştırmada katılımcıların beceri temelli düşünme programı uygulamasında düşünme zorlukları ile karşılaştıkları belirlenmiştir. Bu düşünme zorlukları; eleştirel düşünme ile ilgili zorluklar; uygulanan beceri temelli programdan kaynaklı düşünme zorlukları, fiziksel ve duygusal sorunlardan kaynaklı düşünme zorlukları temaları altında incelenmiştir.

Öğretmen adaylarının uygulama sürecinde düşünme etkinliklerini gerçekleştirirken yaşadıkları düşünme zorluklarından eleştirel düşünme bileşenlerini içeren zorluklar, "eleştirel düşünme zorlukları teması" altında toplanmıştır. $\mathrm{Bu}$ tema altında bilgiyi netleştirememe, nitelikli soru soramama, dar düşünme, çelişkileri fark edememe ve entelektüel tembellik alt temalarına ulaşılmıştır.

Bilgiyi netleştirememe ve nitelikli soru soramama öğretmen adayları tarafından en çok ifade edilen zorluklardır. Öğretmen adayları verilen duruma ilişkin bilgiyi arama ve netleştirme çalışmalarında ve soru sormada zorlanmışlar ve bunu günlüklerine yansıtmışlardır. Örneğin Kübra C. ilk hafta yazmış olduğu günlükte bilgiyi netleştirmede yaşadığı zorluğu "Öğretmenimiz bize örnek durumlar verdi. Biz de o örnek durumlarda verilen ve atlanılan bilgileri bulduk. Bazı sorularda atlanılan bilgileri bulmada zorlandım" (Kübra 1. hafta günlüğü, 05.10.2016) şeklinde yansıtmıştır.” Akile araştırmaya ve keşfetmeye yönelten balıkçı soruları sormada yaşadığı zorluğu günlüğüne “Adam hakkındaki bilgiler eksikti ve ben bilgi elde edecek soru bulamadım" (Akile 2. hafta günlügü, 19.10.2016) şeklinde yansıtmıştır. Fatih ve Kübra ise günlüklerinde soru sormada yaşadıkları zorlukları geleneksel eğitim sistemine ve yetiştirilme tarzına bağlamışlardır.

Farklı bakış açılarıyla bakamamaları ile ilişkili olarak dar düşünme alt teması altında yer alan görüşlerde katılımcıların en çok vurguladıkları ifade önyargıdır. Katılımcılar özellikle ipuçları dersinde tek bir ipucuna takılı kalmalarını önyargılara bağlamışlardır. Örneğin Akile yarı yapılandırılmış görüşmede bu sorunu “Gökdelende ofisi bulunan adam örneğinde tüm ipuçlarını ayrı ayrı yazmamıza rağmen hep resepsiyonist ipucuna takıldık. Adamın kadınla bir ilişkisi olduğu ihtimalini düşündük hep. Bu anlamda da bir önyargl oluştuğundan diğer ihtimaller zaylfladı" (Akile, Görüşme, 03.01.2017) diyerek ifade etmiştir. Gizem ise "Şu an bunu düşündüğüm bana doğru geliyorsa yani o an benim için doğru odur. Onlarınki bana sadece mantıkl gelir ama doğrumu kabul ederim" diyerek benmerkezciliğe vurgu yapmıştır. Araştırmacı ise 2. hafta araştırmacı günlüğünde bu 
G. Çatalbaş ve E, Sarttaş/ Pamukkale Üniversitesi Eğitim Fakültesi Dergisi, 54, 328-356, 2022

durumla ilişkili gözlemini "Gerçekten düşünme yapılarına, kendilerine çok mu güveniyorlar yoksa bu ben merkezli düşünmenin ürünü mü? Bu durumu biraz daha gözlemleyeceğim. Daha erken" (Araştırmacı, 2. hafta günlüğü, 19.10.2016) diyerek aktarmıştır.

Uygulama sürecinde düşünmenin, irdelemenin zor geldiğini, kolaya kaçma, vurdum duymaz olma gibi özelliklerle açıklayan katılımcıların bu düşünme zorluğu entelektüel tembellik alt teması altında ele alınmıştır. Buna ilişkin Ülker " Bazen konuya göre fazla vurdumduymaz olabiliyorum" diyerek Hüseyin ise "sadece bir duruma ya da bir ipucuna takılıp kalıyor olayın diğer taraflarını önemsemiyor ya da görmezden gelmek istiyorum (Hüseyin, 3. hafta günlüğü, 02.11.2016) şeklindeki açıklamasıyla entelektüel tembellik yaşadıklarını ifade eden öğretmen adaylarıdır.

\section{Düşünme zorluklarına bulunan çözümler}

Araştırmada katılımcıların beceri temelli düşünme programı uygulaması boyunca karşılaştıkları düşünme zorluklarına buldukları çözümler "düşünme zorluklarına bulunan çözümler" ana temasında ele alınmıştır. Bu ana tema altında deneyimlerle bağ kurma ve eleştirel düşünme ile ilgili çözümler teması yer almaktadır. Deneyimlerle bağ kurma temasına katılımcıların etkinliklerde karşılaştıkları düşünme zorluklarını çözmede kendi yaşantılarından yola çıkarak hareket etmeleri, olaylarla gerçek yaşam durumları arasında ilişki kurarak daha kolay çözümler bulmalarına ilişkin verilerden ulaşılmıştır.

Katılımcıların beceri temelli program uygulaması boyunca karşılaştıkları düşünme zorluklarına yönelik buldukları çözümler içinde eleştirel düşünme göstergesi olarak yer alan çözümler; başkalarıyla etkileşim”, “alternatiffikirler üretme”, “empati kurma” alt temaları altında ele alınmıştır.

Başkalarıyla etkileşim alt temasına katılımcıların verilen etkinliklerde karşılaştıkları zorluklarını çözmede arkadaşlarıyla iletişim kurdukları ve çözüm üretirken başkalarının fikirlerini dikkate almaları ile ilişkili verilerden ulaşılmıştır. Örneğin Dilek "o fikrini sundu ben fikrimi sundum. Yani ikimizin fikrini ortaya koyup hangisinin daha mantıklı olduğuna karar verdik. Evet haklısın senin fikrin bu olayı çözebilir veya benimki aynı şekilde”(Dilek, Görüşme 03.01.2017) diyerek başkalarıyla etkileşimde bulunarak ortak görüş birliğine vardıklarını ifade etmiştir. Düşünme etkinliklerinde alternatif fikirler üretme alt temasında katılımcılar karşılaştıkları düşünme problemlerini çözmek için alternatif fikirler üreterek çıkarımda bulunmaya çalışmışlardır. Örneğin bu çözüme ilişkin Yusuf yarı yapılandırılmış görüşmede "önce bir elimizdekilere baktık. Olabilecek şeyleri düşündük. Ondan sonra kendimiz bir şeyler ekledik. Sonra kendi eklediğimiz şeylerden olabilitesi yüksek olanları 
düşündük. Bu elimizdeki tahminlere göre. Ondan sonra sonuca ulaşttk"(Yusuf, Görüşme, 02.01.2017)diyerek düşüncesini ifade etmiştir. Empati kurma, katılımcıların düşünme zorluklarını aşmada buldukları çözümlerden biridir. Katılımcılar özellikle sekizinci haftada yer alan duygular dersindeki etkinliklerde karşılaştıkları düşünme zorluklarını empati kurma yoluyla çözüme kavuşturmuşlardır. Empati kurarak çözüm üreten öğretmen adaylarından biri Merve'dir. Merve yarı yapılandırılmış görüşmede düşünme zorluklarına bulduğu çözümü duygular haftasındaki etkinlikle ilişkilendirerek "Evet benim açımdan böyle ama karşımdaki açısından nasıll? Karşımızdaki insan açısııdan nasıl? Bide onu onun açısıından düşünmem gerekiyor diye düşündüm” (Merve, Görüşme, 03.01.2017) şeklinde aktarmıştır.

\section{CoRT 5 düşünme programının öğrenme çıktıları}

Beceri temelli bir düşünme programı uygulamasının kazanımlarına ilişkin verilerin analizinden "CoRT 5 düşünme programının öğrenme çıktıları" ana temasına ulaşılmıştır. Bu ana tema altında programda uygulanan düşünme etkinliklerinin toplumsal sorunlara ilişkin farkındalık geliştirmeye yönelik bulgular bir tema altında toplanırken eleştirel düşünme ile ilgili öğrenme çıktıları ayrı bir tema altında incelenmiş̧ir.

Eleştirel düşünme ilgili öğrenme çıktıları teması altında bilgiyi netleştirme, soru sorma, varsayımları belirleme, çıkarımda bulunma, çelişkileri fark etme, entelektüel cesaret, eleştirel düşünmeye ilişkin farkındalık ve duygu ve düşünce arasındaki ilişkiyi anlama alt temaları elde edilmiştir. Elde edilen bu alt temalar altındaki bulgular eleştirel düşünmenin bilişsel ve duyuşsal boyutuna işaret eden göstergeler olarak ele alınmıştır.

Bilgi ve netleştirme derslerinde düşünsel zorlukla karşılaşan öğretmen adaylarının bilgiyi arama ve açıklığa kavuşturmasına yönelik kazanımlar elde etmeleri ile ilgili veriler bilgiyi netleştirme öğrenme çıktısı altında incelenmiştir. Bu kazanımı Meryem birinci hafta günlüğüne "Etkinliklerdeki problemlere çözüm ararken problemin verilmeyen bilgilerine ulaşmaya çalıştım. Verilmeyen bilgilerin altında neler olabileceğini düşündüm.”'(Meryem,1. hafta günlüğü, 05.10.2016) diyerek yansıtmıştır. Nitelikli soru sorma; bilgi, sorular ve ipuçları dersindeki deneyimlerine ilişkin verilerden ulaşılmış bir temadır. Seda nitelikli soru sormayı programın bir kazanımı olarak "mesela olaylara soru sorarak yaklaşmanin daha temkinli olduğunu fark ettim...Ayrıca olaylara soru sorarak yaklaşmak kişiyi daha da düşündürüyor. Yani düşünme becerisini geliştiriyor. Çünkü her soru düşünülerek soruluyor"” (Seda 2. hafta günlüğü, 19.10.2016) şeklinde günlüğüne aktarmıştır. 
Çıkarımda bulunma çıktısına ilişkin veriler ağırlıklı olarak programının dedektiflik çalışması olarak adlandırıldığı ipuçları dersindeki deneyimlerden elde edilmiştir. Öğretmen adayları ipuçlarını birleştirerek tümevarımsal bir yol izlemişler ve çıkarımda bulunmuşlardır. Örneğin Arife üçüncü hafta günlüğünde “Bugünkü derste ipuçlarl üzerinden olayları çözüme kavuşturma etkinlikleri yaptık. Önce etkinlikteki örnek olay içindeki görünen ipuçlarını belirledik. Daha sonra başka ipuçları bulmaya çalıştık. Örnek olayı daha detaylı bir şekilde düşünerek olayın çözümüne ulaşmaya çalıştık” (Arife, 3.hafta günlügüü, 02.11.2016) diyerek çıkarımda bulunmaya yönelik öğrenme çıktısını ifade etmiştir.

Günlük yaşamda, medyada sık sık karşılaşılan çelişkili ve hatalı çıkarımlar üzerine düşünme çalışmalarının yer aldığı derslerdeki deneyimlere dayalı olarak çelişkileri fark etme bir öğrenme çıktısı olarak belirlenmiştir. Seda hem düşünme zorluğu hem de bir öğrenme çıktısı olarak bu deneyimini 4. Hafta günlüğünde "Mesela bir parti seçim vaadi olarak çok ögretmen atayacağını söylüyor. Ben buna odaklanıp çelişkilerin farkına varamıyorum. Ama bu dersten sonra duruma çok yönlü bakıp tezat ve çelişkileri fark etmeyi öğrendim." (Seda, 4. hafta günlüğü, 16.11.2016) şeklinde ifade etmiştir.

Entelektüel cesaret ve duygu ve düşünce arasındaki ilişkiyi anlama öğrenme çıktıları eleştirel düşünme eğilimlerine işaret eden göstergelerdir. Öğretmen adaylarından Gizem entelektüel cesaret ile ilişkili olarak "aslında bu haftaki konu hoşuma gitti çünkü inançlar konusunda yıkamadiğı̆m tabularım var. Bunları sorgulamak içinde nerden geldiğini nasıl oluştuğunu sorgulamamız gerekiyormuş" (Gizem, 6. hafta günlüğü, 30.11.2016) diyerek yüzleşme eğilimini bir öğrenme çıktısı olarak ifade etmiştir. Arife duygular dersindeki etkinliklere dayalı olarak duygu ve düşünce arasındaki ilişkiyi bir öğrenme çıktısı olarak günlüğüne "derse geç gelen başarılı bir ögrenci, ... 1 gün önce bizi klzdıran ve derse geç gelen öğrenci üzerine nasıl bir davranışta bulunurduk diye konuştuk. İkinci cümlede ögrenciye karşı bir önyargımı olabileceği için farklı bir şekilde davranabileceğimizden bahsettik. Bu dersten ögrendiklerim duygularımın düşüncelerimi nasıl yönettiği ile ilgiliydi. (Arife, 8. hafta, günlüğü, 14.12.2016) şeklinde yansıtmıştır.

Özetle, program uygulamasında karşılaşılan düşünme zorluklarında, bu zorluklara bulunan çözümlerde ve programın öğrenme çıktılarında eleştirel düşünmeye işaret eden göstergeler yer almaktadır. Bu bulgular doğrultusunda araştırmanın birinci sorusuna yanıt olarak CoRT 5 düşünme programının eleştirel düşünme göstergeleri taşıdığı söylenebilir. 


\section{CoRT 5 Düşünme Programının Eleştirel Düşünme Beceri ve Eğilimlere Katkıları}

Araştırmanın ikinci sorusu olan "CoRT 5 düşünme programı eğitimi, sınıf öğretmeni adaylarının eleştirel düşünme beceri ve eğilimlerine ne tür katkılar sağlamıştır?" sorusuna yanıt aramak amaciyla yapılan verilerin analizinden "CoRT 5 Düşünme Programının Eleştirel Düşünmeye Yönelik Katkıları" ana temasına ulaşılmıştır. Bu ana tema altında eleştirel düşünme becerilerine yönelik katkılar ve eleştirel düşünme eğilimlerine yönelik katkılar olarak iki tema yer almaktadır.

\section{CoRT 5 düşünme programının eleştirel düşünme becerilerine yönelik katkıları}

Öğretmen adaylarıyla yapılan görüşme verilerinin analizinde programın kendi düşünme yapılarına katkıları; eleştirel düşünme becerilerini transfer etme, fikirleri derinlemesine analiz etme ve öz düzenleme alt temaları altında ele alınmıştır. Bu katkılar eleştirel düşünme becerileriyle ilişkilidir. $\mathrm{Bu}$ nedenle eleştirel düşünme becerilerine yönelik katkılar teması altında ele alınmıştır.

Katılımcıların uygulanan düşünme programının katkısı içinde en çok vurguladıkları katk1 eleştirel düşünme becerilerini transfer edebilmedir. Katılımcılar, program uygulaması sonucu elde ettikleri becerileri uygulama yaptıkları ilkokulda ve günlük yaşamlarında kullanabildiklerini ifade etmiştir. Örneğin Kübra bilgi dersindeki etkinlikleri öğretmenlik uygulamasında nasıl kullandığını bir öğrenciyle ilgili yaşadığı durumla ilişkilendirerek “Öğrenciye bakışımız bile değişiyor. O hafta staj sınıfında bir çocuk vardı. Hiçbir şekilde ders dinlemiyor. Çok haşarl falan. Sordum niye bu şekilde diye. Annesinin babasının ayrılacă̆ını öğrendim. Atlanan bilgi ile bir sonuca ulaşmış oldum” (Kübra, Görüşme, 03.01.2107) şeklinde ifade etmiştir. Gamze ise "Hani önceden sadece tek düzey hani dinliyordum. Çok fazla bir sorgulama içine falan girmem hani öyle yargılamam, düşünmem. Ama daha sonrada hani bir haber okuyorum. Bir alt yazı var bu alt yazınında içeriği gerçekten de haber uyuyor mu, çelişki var mı diye falan bakıyorum”(Gamze, Görüşme, 04.01.2017) diyerek bu becerileri günlük hayata nasıl transfer ettiğini açıklamıştır.

Uygulanan programın eleştirel düşünme becerilerine yönelik diğer bir katkısı analiz etme becerileriyle ilişkilidir. Analiz etme becerilerindeki kazanımına ilişkin araştırmacı uygulama başında verdiği gazete haberini program sonunda tekrar vererek süreci gözlemlemiş ve bunu günlüğüne "Merve haberi sınıfa (ilk) sunduğumda ülkemizin bu göçmenleri kabul etmemesi gerektiğini ifade ederken uygulama sonunda farklı bir şekilde ele aldı̆̆ııı açıkladı. Aynı haberde bilmediği neler var, devlet için olumlu ve olumsuz 
G. Çatalbaş ve E, Sarıtaş/ Pamukkale Üniversitesi Eğitim Fakültesi Dergisi, 54, 328-356, 2022

yönleri, insani etkileri nelerdir sorgulamasına girerek açıkladı"(Araştırmacı günlüğü, 4 Ocak 2017) şeklinde aktarmıştır.

Katılımcılar CoRT 5 düşünme programının bilişsel etkinliklerine yönelik düşüncelerini yansıtırken zaman zaman kendi düşünme süreçlerini değerlendirmişlerdir. $\mathrm{Bu}$ bulgular öz düzenleme becerilerine katkı olarak ele alınmıştır. Bu yönde katkı sağladığını ifade eden katılımcılardan Gizem, "Evet. Sorgulama becerimi çok arttırdı. Genelde stajdan çıktığımda eve giderken düşünüyordum yani. Olması gereken bu ama ben bunu niye yapamıyorum diye " (Gizem, Görüşme, 03.01.2017) diyerek görüşünü aktarmıştır. Gizem görüşmenin devamında kendi düşünme yapısında yer alan aşırı genelleme, karamsar olma, akılcı olmayan inançlarının farkına varıp bu durumu düzeltmeye çalıştığını ifade etmiştir.

\section{CoRT 5 düşünme programının eleştirel düşünme eğilimlerine yönelik katkıları}

Öğretmen adayları uygulanan düşünme programının, duyuşsal boyutu oluşturan eleştirel düşünme eğilimlerine de katkı sağladığı yönünde görüşler belirtmişlerdir. $\mathrm{Bu}$ görüşler düşünme eğilimlerine yönelik katkılar temasında ele alınmıştır. Bu tema altında katılımcılar, programın eleştirel düşünmeye ilişkin farkındalık, açık fikirlilik, sistematiklik, öz düzeltmede isteklilik ve eleştirel düşünmede kendine güven boyutunda katkılar sağladığını ifade etmişlerdir.

CoRT 5 düşünme programının eleştirel düşünme eğilimlerine katkıları içinde katılımcılar tarafından en fazla vurgulanan katkı eleştirel düşünmeye ilişkin farkındalığı artırmasıdır. Örneğin Dilek, CoRT 5 düşünme programının eleştirel düşünmeye ilişkin farkındalığına sağladığı katkıyı, fikirler dersindeki kazanımlarla ilişkilendirerek açıklamıştır. Dilek eleştirel düşünür olabilmek için sahip olunan fikirlerin kaynağının bilinmesi gerektiğini ve programın sağladığ 1 katkıyı "farkındalık oluşturdu derslerde. Dedim yani ben böyle düşünüyorum ama bunu gerçekten kendim mi düşündüm yoksa bunu bana annem babam mı kattı? kendi kendime sorgulama yaşadım. Düşüncemin kaynağını bilmeden nasıl eleştirel olabilirim ki. İşte program bana bu anlamda fayda sağladı" (Dilek, Görüşme, 03.01.2107) diyerek açıklamıştır. Merve ise olaylara karşı önyargılı yaklaştığını fark etmesinin programın bir katkısı olduğunu "daha önyargılı yaklaşlyordum her şeye, her olaya, insanlara karşı falan. Ama (şimdi) karşımdakinin yaptı̆̆ bir hareketin veya söylediği bir şeyin altında farklı nedenler yatabileceğini veya, benim düşündüğümden farklı bir şeyden böyle davranabileceğini, Mutlaka bir nedeni vardır yani. Onun farkına vardım eğitimlerde" (Merve, Görüşme, 03.11.2017) diyerek yarı yapılandırılmış görüşmede 
aktarmıştır. Akile ise bu programın farkındalık kattığını ama tamamen düşünme yapısını değiştirmediğini ifade etmiştir.

Açık fikirlilik teması altında katılımcılar, programın başkalarını anlama ve dinleme, empati yapma, farklı düşüncelere saygı duyma, olaylara farklı açıdan bakabilme ve tarafsız olma boyutunda duyuşsal becerilere olan katkılarını dile getirmişlerdir. Kendini düşüncelerinde katı biri olarak tanımlayan Hüseyin düşünme yapısının değişmesinin zor olduğunun farkında olmakla birlikte açık fikirli olmaya ilişkin bu katkıyı "Ben hocam, düşüncelerimde katı biriyimdir. Hani bu eğitimden sonra düşüncelerimi de hani direk böyle değiştirmedim. Katılı̆̆ım hala devam etti ama biraz daha kendimi yumuşattım. Karşımdakilerin düşüncelerini de göz önünde bulundurmaya başladım. (Hüseyin, Görüşme, 27.12.2016) diyerek açıklamıştır.

Katılımcıların düşünme etkinliklerinde verilen durumlara ilişkin sorgulama yaparken, mantık yürütme aşamasında, planlı ve özenli bir çalışma süreci takip etmeye gayret gösterdikleri gözlenmiştir. Bu veriler CoRT 5 düşünme programı uygulamasının bir katkısı olarak sistematiklik alt temasında ele alınmıştır. Merve programın düşünmeyi organize edebilme eğilimine katkı sağladığını görüşmede "eleştirmeliyim ama nasıl yapabilirim. Bunu bu ĕgitimler sonucunda daha iyi anladım...Aslında bildiğimiz şeylerin sadece nasıl yapıldı̆̆ını bilmiyorduk. Bunu yapmamı gerekiyor ama nasıl yapabilirim bunu hiç bilmiyordum” (Merve, Görüşme, 03.01.2017) diyerek açıklamıştır

Katılımcılar uygulama sürecinde yer alan düşünme etkinlikleriyle kendi düşünme yapılarını gözden geçirmişler, düşünme süreçlerinde yapmış oldukları hataları kabul ederek, bu hatalarından öğrenme eğilimi göstermişlerdir. Bu verilere ilişkin bulgular öz düzeltmede isteklilik alt temasında ele alınmıştır. Katılımcılardan Kübra programı değerlendirdiği görüşmede bu katkıyı tuval ve renklerle ilişkilendirerek şöyle açıklamıştır:

Bu düşünce eğitimi en güzel renklerden biri oldu açıkçası benim yaşam tuvalimde. Hani şey vardı böyle bugüne kadar. Ben hep olumsuzluklarını görmek istediğim için açıkçası her gelen sanki siyah firçalardı böyle. Ama düşünme eğitimi ile birlikte bilmiyorum. Daha böyle renkli bir firça oluştu. Ve orda böyle bir siluet oluştu. Ve o siluet benim kendi siluetim oldu (Kübra, Görüşme, 03.01.2017).

Eleştirel düşünmede kendine güven katkısına yönelik sadece bir katılımcı görüş belirtirken iki katılımcı uygulanan programın eleştirel düşünme beceri ve eğilimlerine 
doğrudan bir katkı sağlamadığını ve bir katılımcı da bir katkısının olup olmadığını fark edemediğini ifade etmiştir.

\section{Sınıf Öğretmeni Adaylarının Eleştirel Düşünme Eğitimine Yönelik Görüşleri}

Araştırmanın üçüncü sorusu olan "sınıf ögretmeni adaylarının eleştirel düşünme eğitimine yönelik görüşleri nelerdir?" sorusuna yanıt aramak amaciyla uygulama sonunda gerçekleştirilen yarı-yapılandırılmış görüşmelerin analizinden "Eleştirel Düşünme Eğitimine Yönelik Görüşler” ana teması elde edilmiştir. Bu görüşler; beceri temelli eleştirel düşünme eğitimi, konu alanıyla bütünleştirilmiş eleştirel düşünme eğitimi ve karma yaklaşımla eleştirel düşünme eğitimi temaları altında incelenmiştir.

Öğretmen adaylarının eleştirel düşünmenin tüm derslerden bağımsız, ayrı bir ders olarak verilmesi yönündeki görüşleri, beceri temelli eleştirel düşünme eğitimi teması altında toplanmıştır. Araştırmanın çalışma grubunda yer alan 14 öğretmen adayı genel olarak düşünme eğitimi, özel olarak da eleştirel düşünme eğitiminin beceri temelli bir ders olarak eğitim fakülteleri programlarında yer alması gerektiğini ifade etmiştir. Örneğin Dilek bu görüşlerini şöyle aktarmışlardır:

Bence böyle bir eğitim verilmeli çünkü bu dersi alıncaya kadar biz de tam olarak düşünmüyormuşuz. Ben bunu fark ettim. Yani biz de yüzeysel bakıyormuşuz her şeye. Yani biz böyle yaparken bunu çocuklara nasıl aşılayacağız diye. Çocuklardan bunu nasıl bekleyeceğiz öyle düşünmelerini? Sorgulamalarını biz bile sorgulamıyormuşuz yani. Kabul ediyormuşuz direk her şeyleri. Bence kesinlikle böyle bir eğitim şart (Dilek, Görüşme, 03.01.2017).

Ülker ise beceri temelli eleştirel düşünme eğitiminin sadece eğitim fakülteleriyle sınırlı kalmamasını "hatta eğitim fakültesi formasyonu olarak da değil insanlar arası ilişkilerde de büyük önem taşıdığını düşünüyorum. Hatta bütün üniversitedeki bölümlere ortak ders olarak gelebilir yani. Inkılap, Ingilizce gibi” (Ülker, Görüşme, 05.01.2017) diyerek aktarmıştır. Gizem'e göre mesleğine devam eden öğretmenlerin de bu eğitimi almaları gerekir. Bu düşüncesini "Çünkü önce kendi düşünceni değiştirebilesin ki düzgün düşünebilesin ki çocuğun da düşüncesini değiştirebilsin” diyerek gerekliliği açıklamıştır. Öğretmen adaylarına göre bu eğitim zorunlu derslerle ilkokullarda verilmelidir. Arife bu gerekliliği “Böyle bir dersin olması bence yararlı olur diye düşünüyorum. İlkokullarda zaten en temelden başlamall. Yani hani diyoruz ya ă̆aç yaş iken eğilir düşüncesinden gidersek mesela 1. Sinıfta başlamalı zaten. Öyle bir dersin olması gerekiyor” (Arife, Görüşme, 
04.01.2017) diyerek açıklamıştır. Seda ve Gizem toplumsal olarak yaşanan çatışmalarda eleştirel düşünme becerileri eksikliğine vurgu yaparak bu becerilerin kazanılmasının toplum için önemli olduğunu düşünmektedirler. Seda bu görüşünü yarı yapılandırılmış görüşmede "Hatta diyorum ki hani keşke gerçekten yani ne bileyim böyle halk ĕgitimlerde bir yerlerde bu eleştirel düşünce kursları olsa. Keşke hani halkımızda alabilse hani ne bileyim annemler falan. Hani böyle gidip yani herkes bence almalı diye düşünüyorum. Bilmiyorum çünkü ben çok etkilendim”(Seda, Görüşme, 02.01.2017) diyerek aktarmıştır.

Öğretmen adaylarının hem öğretmen yetiştirme hem de ilkokul öğretim programlarında eleştirel düşünmenin derslerin içine yayılarak konu alanı içinde yer alması gerektiğini ifade eden görüşleri "konu alanıyla bütünleştirilmiş eleştirel düşünme eğitimi” teması altında incelenmiştir. Hasret bu düşüncesini, "Her dersin içinde olması gereken bir şey bence”"(Hasret, Görüşme, 27.12.2016) diyerek aktarmıştır. Gökhan ise, “Mesela ayrı bir ders olmasına da gerek yok hocam. Bütün derslerde kullanabiliriz yani. Bütün derslerin içeriğine katabiliriz. Yöntem ve tekniklerimizi ona göre uygulayabiliriz. Tartışma ortamları yaratabiliriz farklı düşünme becerilerine yönelik” (Gökhan, Görüşme, 03.01.2017) diyerek görüşlerini açıklamıştır. Katılımcılara göre konu alanıyla bütünleştirilmiş bir yaklaşımla ilkokullarda, her ders düzeyinde problem çözme, drama, beyin firtınası, münazara gibi öğretim yöntem ve teknikleri kullanılarak eleştirel düşünme becerileri kazandırılabilir. $\mathrm{Bu}$ görüşe ilişkin örneğin Emre "Illkokullarda drama. Benim aklıma ilk gelen o. Drama tekniği. Öğretmenin günlük olaylardan sebep ögrencilere birşeyler okuması. Canlandırmalarını istemeleri. Ya da beyin firtınalarıyla düşüncelerini açı̆̆a çıkarması.” (Emre, Görüşme, 03.01.2017) diyerek düşüncesini aktarmıştır.

Karma yaklaşımla eleştirel düşünmenin daha etkili öğretilebileceğinin düşünen dört katılımcı ise beceri temelli ve konu alanıyla bütünleştirilmiş yaklaşımın birleşmesi yönünde görüşlerini ifade etmiştir. Bu görüşü aktaran katılımcılara göre almış oldukları bir dersle temel eleştirel düşünme becerileri verilip farklı derslerin içeriği içinde bu becerilerin uygulanmasına olanak verilirse eleştirel düşünme etkili bir şekilde öğretilebilir. Örneğin Kader bu görüşünü “İlkokullarda da çocuklara ayrı ders olarak verilebilir. Sonra derslerle kaynaştırmaya çalışırız. "( Kader, Görüşme, 05.01.2017) diyerek ifade etmiştir.

\section{Tartışma ve Sonuç}

Araştırmaya bütünsel olarak yaklaşabilmek amacıyla araştırma soruları dikkate alınarak sonuçlar verilip tartışılmıştır. İlk aşamada beceri temelli program uygulamasıyla eleştirel düşünmeye yönelik ortaya çıkan göstergeler, ikinci aşamada eleştirel düşünme beceri ve 
eğilimlerine katkılar ve son aşamada ise eleştirel düşünme eğitimine yönelik görüşlere ilişkin bulgular tartışılmıştır.

CoRT 5 düşünme programı uygulama esnasında, karşılaşılan düşünme zorluklarında, bu zorluklara bulunan çözümlerde ve öğrenme kazanımlarında eleştirel düşünmeye ilişkin göstergeler incelenmiştir. Bilgiyi netleştirememe, nitelikli soru soramama, dar düşünme, çelişkileri fark edememe ve entelektüel tembellik olarak belirlenen düşünme zorlukları eleştirel düşünme bileşenlerini işaret eden bulgular olarak ele alınmıştır. $\mathrm{Bu}$ durumu Nosich (2015) eleştirel düşünme standartlarını engelleyen etmenler, Paul ve Elder (2013) düşünme yanılsamaları; Sternberg ve Grigorenko (2000) ve Gündoğdu (2009) ise eleştirel düşünmenin önündeki engeller olarak ifade etmiştir. Öğretmen adayları karşılaştıkları düşünsel zorlukların kaynağının ön yargılar, geleneksel eğitim, yetiştirilme tarzı, odaklanamama, takılıp kalma ve ben merkezli düşünme gibi olumsuz yaşantılar olduğunu ileri sürmüşlerdir. Paul ve Elder'a (2013) göre bireyin içinde doğduğu kültür, ortam, ailenin taşıdığı inançların yaratmış olduğu değerler, çevreden kaynaklı bakış açıları düşünceleri etkileyen önemli faktörlerdir. İpşiroğlu (1993) bu durumu "konserve çocuklar" metaforuyla otoriter eğitim sistemi, geleneksel, kalıplaşmış eğitim yaklaşımları ile bir çıkmaz içinde sıkışıp kalan soru sormayan, sorgulamayan, düşünmeyen çocuklarla açıklamıştır

Düşünme programı uygulama esnasında verilen etkinliklerde düşünme zorluklarıyla karşılaşan öğretmen adayları bu zorlukları arkadaşlarıyla etkileşime girerek, alternatif fikirler üreterek ve empati yaparak aşmaya çalışmaları eleştirel düşünmeyi bir kaynak olarak kullandıklarının bir göstergesidir. Arkadaşlarıyla etkileşime girme, alternatifler üretme ve açık fikirlilik içinde yer alan empati yapma alan yazında yer alan eleştirel düşünme eğilimleri sınıflamalarında (Bailin ve diğerleri, 1999; Ennis,1985 (b); Facione ve Facione,1996; Halpern, 2003 ve Paul ve Elder ,2013) yer alması yine eleştirel düşünme göstergeleri olduğunun bir kanıtıdır.

Öğretmen adaylarının eleştirel düşünmeye yönelik ne tür kazanımların gerçekleştirildiğine ilişkin elde edilen bulgular öğrenme çıtıları ana temasında ele alınmıştır. $\mathrm{Bu}$ ana tema içinde bilgiyi netleştirme, soru sorma, varsayımları belirleme, çıkarımda bulunma, çelişkileri fark etme olarak ifade edilen öğrenme çıktıları eleştirel düşünmenin becerileri boyutuyla ilişkilidir. Entelektüel cesaret, eleştirel düşünmeye ilişkin farkındalık, duygu ve düşünce arasındaki ilişkiyi anlama olarak ifade edilen öğrenme çıktıları ise eleştirel düşünmenin eğilim boyutunun göstergeleridir Araştırmada elde edilen 
öğrenme çıktıları, eleştirel düşünme alan yazınında farklı araştırmacıların (Bailin ve diğerleri, 1999; Beyer, 1984; Demirel, 2007; Ennis, 1985b; Facione, 1990; Halpern, 2003; Paul ve diğerleri, 1989; Paul ve Elder, 2013; Watson ve Glaser, 2010) eleştirel düşünme sınıflamalarında yer almaktadır. Ancak uygulanan düşünme programının öğrenme çıktıları arasında, eleştirel düşünme becerileri sınıflamalarına ilişkin alanyazınında (Beyer, 1984; Ennis, 1985b; Facione, 1990; Paul ve diğerleri, 1989 ve Watson ve Glaser, 2010;) değerlendirme boyutuna (bilgi kaynaklarının güvenirliğini, kanıtları, iddiaları ve karşı görüşleri değerlendirme) ilişkin herhangi bir göstergeye rastlanmamıştır. Benzer sonuç AlEdwan'ın (2011), CoRT 1 ve CoRT 2 programının düşünme becerilerine etkisinin incelendiği deneysel çalışmasında ve Yine Özüberk'in (2002) araştırmasında da elde edilmiştir. $\mathrm{Bu}$ beceriye yönelik etkinliklerin olmayışı programın bir sınırlığı olarak açıklanabilir.

Eleştirel düşünmenin eğilim boyutuna işaret eden öğrenme çıktıları ise entelektüel cesaret, eleştirel düşünmeye ilişkin farkındalık, duygu ve düşünce arasındaki ilişkiyi anlama alt temaları altında incelenmiştir. Bunlar içinde entelektüel cesaret altında öğretmen adaylarının kendi düşünme yapılarını sorgulama cesareti göstererek kendilerini eleştirmelerini, Paul ve Elder (2013) entelektüel özellik olarak açıklamaktadır. Uygulanan programın bir öğrenme çıktısı olarak ele alınan eleştirel düşünmeye ilişkin farkındalık oluşmasını Costa (2006), beceri temelli programların bir kazanımı olarak açıklamıştır. Araştırmada, beceri temelli düşünme programı uygulamasının eleştirel düşünmenin eğilim boyutuna işaret eden son öğrenme çıktısı duygu ve düşünce arasındaki ilişkiyi anlamayla ilişkili olarak Nosich (2015) eleştirel düşünme için duyguların gerekli olduğunu, düşünmenin duygulardan veri sağladığını açıklayarak duygu ve düşünce arasındaki ilişkiyi vurgulamıştır.

Araştırmanın ikinci sorusuna yanıt aramak amacıyla elde edilen bulgulardan beceri temelli düşünme programı uygulamasının, sınıf öğretmeni adaylarının beceri ve eğilimlerine katkı sağladığı sonucuna ulaşılmıştır. CoRT 5 düşünme programının öğretmen adaylarının eleştirel düşünme becerilerine sağladığı katkılar, CoRT düşünme programı uygulamalarının gerçekleştirildiği araştırmaların (Al-Edwan, 2011; Aybek, 2006; Barak ve Doppelt, 2006; Bayrak, 2014; Korkmaz ve Keleş, 2014; Ritchie ve Edwards, 1996; Rule ve Stefanick, 2012;) sonuçlarıyla benzerlik göstermektedir. Tok'un (2008) okul öncesi öğretmen adaylarıyla gerçekleştirdiği düşünme becerilerine yönelik düşünme programı uygulamasında 
G. Çatalbaş ve E, Sarıtaş/ Pamukkale Üniversitesi Eğitim Fakültesi Dergisi, 54, 328-356, 2022

eğitim grubunun programa yönelik görüşleri incelenmiş ve derste yapılan etkinliklerin onları olumlu yönde geliştirdiği sonucuna ulaşılması da araştırma bulgusunu desteler niteliktedir.

Öğretmen adaylarının beceri temelli düşünme programı uygulamasının eleştirel düşünme becerilerine katkısı olarak en çok vurguladığı katkı eleştirel düşünme becerilerini yeni durumlara transfer edebilmedir. Bu sonuç Aybek'in (2006) beceri temelli CoRT 1 düşünme programını uygulamasıyla öğretmen adaylarının öğrendikleri eleştirel düşünme becerilerini günlük hayatta kullanmaya başladıklarını ve çevresindeki diğer insanlara da bu becerileri günlük hayatta kullanma konusunda bilinçlendirdiklerini belirtmeleri araştırma sonucuyla örtüşmektedir.

Eleştirel düşünmeye ilişkin farkındalık, açık fikirlilik, sistematiklik, öz düzeltmede isteklilik ve eleştirel düşünmede kendine güven alt temalarında ele alınan katkılar uygulanan programın eleştirel düşünme eğilimlerine katkılar teması altında ele alınmıştır Eleştirel düşünme eğilimlerine katkı sağlamasına ilişkin araştırma sonucu, Bayrak (2014) tarafından ilkokul 4. Sınıflarda Fen Bilgisi dersinde CoRT 1 düşünme programı uygulamasının, öğrencilerin eleştirel düşünme eğilimlerinde artışın görülmesi sonucuyla paralellik göstermektedir. Eleştirel düşünmeye ilişkin farkındalıkların artırması öğretmen adayları tarafından en çok vurgulanan katkı olmuştur. Eleştirel düşünmenin beceri temelli öğretimine savunan araştırmacılar, (Beyer, 1984; De Bono, 2002; Ennis, 1985b; Fisher, 1995; Lipman, 1988 and McCall, 2017) nasıl düşünüleceğini öğretmesi bakımından bu programların farkındalık geliştirdiğini belirtmektedir.

Araştırmada son olarak sınıf öğretmeni adaylarının eleştirel düşünme eğitimine yönelik görüşleri belirlenmiştir. Bu görüşler; beceri temelli eleştirel düşünme eğitimi, konu alanıyla bütünleştirilmiş eleştirel düşünme eğitimi ve karma yaklaşımla eleştirel düşünme eğitimi temaları altında incelenmiştir.

Öğretmen adayları ağırlıklı olarak gerek öğretmen yetiştirme programlarında gerekse ilkokul programlarında beceri temelli eleştirel düşünme eğitimini önermektedir. Eleştirel düşünme eğitiminin beceri temelli bir yaklaşımla verilmesinin gerekliliğini savunan araştırmacılar (Beyer, 1984; De Bono, 2002; Ennis, 1985b; Fisher, 1995; Lipman, 1988; McCall, 2017) bu becerinin öğretilebilir ve transfer edilebilir olduğunu ileri sürmüştür. Öğretmen adaylarına göre hizmet öncesi öğretmen yetiştirme programlarında beceri temelli programlarla eleştirel düşünme eğitimi ilk sınıflardan itibaren yer almalıdır. Benzer bir sonuç Aybek'in (2006) beceri temelli gerçekleştirilen düşünme eğitimi dersini alan 
öğretmen adaylarının eğitim fakültelerinde "Düşünme Eğitimi” dersinin zorunlu bir ders olarak ve daha alt sınıflarda verilmesi gerektiği görüşüyle benzerlik göstermektedir.

Öğretmen adaylarının bazılarına göre eleştirel düşünme konu alanıyla bütünleştirilmiş bir yaklaşımla daha etkili öğretilebilir. Bu görüşü, Han ve Brown'ın (2013) okul öncesi öğretmen adaylarına Paul ve Elder'ın eleştirel düşünme modeli uygulamasının eleştirel düşünmeye yönelik etkilerini incelediği araştırma sonucunu destekler niteliktedir. Araştırma sonucunda eleştirel düşünmenin derslerle bütünleştirilmesinin öğretmen adaylarının eleştirel düşünmeye yönelik eğilimlerini olumlu yönde arttırdığg, eleştirel düşünme ögelerini ve standartlarını derslere daha iyi uyguladıkları görülmüştür. Konu alanıyla bütünleştirilmiş yaklaşımı öneren bazı öğretmen adayları ilkokullarda her ders düzeyinde farklı öğretim yöntem ve teknikleri kullanılarak eleştirel düşünme becerileri kazandırılabileceğini düşünmektedir. Miri, David ve Uri’nin (2007) yapmış olduğu araştırma bulgularına göre öğretmenler, gerçek hayattan alınmış problem durumları vererek, açık uçlu sınıf tartışmaları ve sorgulamaya dayalı öğrenme ortamlarını düzenlerse öğrencilerin eleştirel düşünme becerilerini geliştirebilirler.

Karma yaklaşıma yönelik görüşlerini aktaran öğretmen adayları ise, beceri temelli dersin yanında, programda yer alan diğer derslerin içeriğinde yer verilen bir eleştirel düşünme öğretiminin daha etkili olacağını düşünmektedir. Bu görüşler, Karsantık’ın (2016) yaptığı araştırmada öğretmen adaylarının düşünme becerilerinin öğretiminde karma yaklaşımın, en etkili yaklaşım olduğu görüşüyle benzerlik göstermektedir. Abrami ve diğerleri (2008) de 117 çalışmanın incelendiği meta analiz araştırmasında, eleştirel düşünme becerilerinin öğretiminde dolaylı yaklaşımın en az etkili, karma yaklaşımın ise en etkili yaklaşım olduğu sonucuna ulaşmışlardır.

$\mathrm{Bu}$ araştırmada kapsamında eleştirel düşünmenin, sınıf öğretmeni adaylarında 10 haftalık, CoRT 5 düşünme programıyla geliştirilebileceği ortaya konulmuştur. Bu sonuçlar eleştirel düşünme becerileri ve eğilimlerine yönelik elde edilen göstergelerle desteklenmiştir. Bu bağlamda eleştirel düşünme eğitiminde özelde CoRT 5 düşünme programının genelde ise beceri temelli düşünme programlarının öğretmen yetiştirmede kullanılabileceği söylenebilir. Yapılacak boylamsal çalışmalarla öğretmen yetiştirme döngüsünde düzenlemeler yapılabilir. 21. yüzyıl becerisi içinde yer alan eleştirel düşünme eğitimi, örgün ve yaygın eğitimle toplumun her kesimine verilerek yaşam boyu öğrenmenin bir parçası olarak değerlendirilebilir. 
Etik Kurul İzin Bilgisi: Bu makale 2018 yılında tamamlanmış " CoRT 5 Düşünme Programı Aracılı̆̆ıyla Sınıf Öğretmeni Adaylarının Eleştirel Düşünme Becerileri ve Eğilimleri" başlıklı doktora tezinden üretilmiştir. Araştırma verileri 2020 yılı öncesi toplandığı için etik kurul izni bulunmamaktadır.

Yazar Çıkar Çatışması Bilgisi: Makalenin yazarları arasında çıkar çatışması bulunmamaktadır.

Yazar Katkısı: Yazarlar çalışmaya eşit oranda katkı sağlamıştır

\section{Kaynakça}

Abrami, P.C., Bernard, R.M., Borokhovski, E., Wade, A., Surkes, M.A., Tamim, R., \& Zhang, D. (2008). Instructional interventions affecting critical thinking skills and dispositions: A stage 1 meta-analysis. Review of Educational Research, 78(4), $1102-$ 1134.

Al-Edwan, Z.S. (2011). The effectivenes of a trianing program based on cognitive reserarch trust strategies to develop seventh grade students' critical thinking in history course, Journal of Social Sience,7(3), 436-442.

Aybek, B. (2006). Konu ve beceri temelli eleştirel düşünme öğretiminin öğretmen adaylarının eleştirel düşünme eğilimi ve düzeyine etkisi. Yayımlanmamış doktora tezi, Çukurova Üniversitesi, Adana.

Bailin, S., Case, R., Coombs, J. R. \& Daniels, L. B. (1999). Conceptualizing critical thinking. Journal of Curriculum Studies, 31(3), 285-302.

Barak, M. \& Doppelt, Y. (1999). Integrating the Cognitive Research Trust (CoRT) Programme for creative thinking into a project-based technology curriculum. Research in Science \& Technological Education, 17(2), 139-151.

Bayrak, Ç. (2014). CoRT 1 düşünme programının "yaşamımızdaki elektrik" ünitesinde kullanılmasının öğrencilerin akademik başarılarına, bilimsel yaratıcılıklarına ve eleştirel düşünme eğilimlerine etkisi. Yayınlanmamış yüksek lisans tezi, Adnan Menderes Üniversitesi, Aydın.

Beyer, B. K. (1984). Improving thinking skills: practical approaches. Phi Delta Kappa International, 65, 556-560. 
Beyer. K. B. (1985). Practical strategies for direct instruction in thinking skills. In A.Costa (Ed.). Developing minds Vol 1 (145-150). Alexandria: Virginia.ASCD.

Braun, V. and Clarke, V. (2006). Using thematic analysis in psychology. Qualitative Research in Psychology, 3(2), 77-101.

Case, R. \& Wright, I. (1997). Taking seriously the teaching of critical thinking. Canadian Social Studies, 32(1), 12-19.

Commission of Effective Teachers and Teaching [CETT]. (2011). Transforming teaching: Connecting professional responsibility with student learning. http://www.nea.org/assets/docs/Transformingteaching2012.pdf sayfasindan erişilmiştir.

Costa, Arthur L. (2006). Five themes in thought-full curriculum. Thinking Skills Creativity, $1,62-66$.

Cüceloğlu, D. (1994). İyi düşün doğru karar ver (6. Bask1). İstanbul: Sistem Yayınc1lık.

Çetinkaya, Z. (2011). Türkçe öğretmen adaylarının eleştirel düşünmeye ilişkin görüşlerinin belirlenmesi. Ahi Evran Üniversitesi Ĕ̆itim Fakültesi Dergisi, 12(3), 93-108.

De Bono, E. (2002). CORT thinking lessons CD. Cavendish information product Ltd. 10 Cavendish Road, Oxford OX27TW, Uk.

De Bono, E. (2011). Kendine düşünmeyi ögrret (3. Bask1). İstanbul: Remzi Kitapevi.

Demirel, Ö. (2007). Kuramdan uygulamaya ĕgitimde program geliştirme. Ankara: PegemA Yayıncilık.

Dewey, J. (1991). How we think. NewYork: Pomethus Books.

Doğanay, A. (2000). Yaratıcı öğrenme, A. Şimsek, (Ed.), Sinıfta Demokrasi içinde (171210). Ankara: Eğitim-Sen Yayınları.

Doğanay, A. \& Ünal, F. (2006). Eleştirel düşünmenin öğretimi. A. Şimşek (Ed.), İçerik Türlerine Dayalı Öğretim (209-264). Ankara: Nobel Yayınevi

Doğanay, A., Taş, M. A., \& Erden, Ş. (2007). Üniversite öğrencilerinin bir güncel tartışmalı konu bağlamında eleştirel düşünme becerilerinin değerlendirilmesi. Kuram ve Uygulamada Ĕ̌itim Yönetimi, 52(52), 511-546.

Ennis, R. H. (1985). A logical basis for measuring critical thinking skills. Educational Leadership, 43(2), 44-48. 
Ennis, R.H. (1985). Goals for a critical thinking curriculum. A.Costa (Ed.), In Developing Minds, Vol 1 (68-71). Alexandria: Virginia.ASCD.

Facione, P. A. (1990). Critical thinking: A statement of expert consensus for purposes of educational assessment and instruction. Research Findings and Recommendations. Prepared for the Committee on Pre-College Philosophy. New York NY: American Philosophical Association.. ERIC Doc. ED 315-423.

Facione, N. C., Facione, P. A. (1996). Externalizing the critical thinking in knowledge development and clinical judgment. Nursing Outlook, 44, 129-136.

Facione, P. A. (2013). Critical thinking: What it is and why it counts. Millbrae, CA: Measured Reasons and the California Academic Press. ISBN 13: 978-1- 891557-071. http://www.insightassessment.com/pdf sayfasından erişilmiştir.

Fisher, R. (1995). Teaching children to think. UK: Stanley Thornes Ltd.

Fisher, R. (2001). Philosophy in primary schools: fostering thinking skills and literacy. Reading, 35(2), 67-73.

Gündoğdu, H. (2009). Eleştirel düşünme ve eleştirel düşünme öğretimine dair bazı yanılgılar. Celal Bayar Üniversitesi Sosyal Bilimler Enstitüsü, 7(1), 57-74.

Gürkaynak, İ.,Üstel, F. ve Gülgöz, S. (2008). Eleştirel düşünme (3. Bask1). İstanbul: Eğitim Reformu Girişimi.

Hager, P. ve Kaye, M. (1992). Critical thinking in teacher education: A process-oriented research agenda. Australian Journal of Teacher Education, 17(2), 26-33.

Hager, P., Sleet, R., Logon, P.\& Hooper, M. (2003). Teaching critical thinking in undergraduate science courses. Science \& Education, (12), 303-313.

Halpern, D. F. (1998). Teaching critical thinking for transfer across domains: Disposition, skills, structure training, and metacognitive monitoring. American Psychologist, 53(4), 449-455.

Halpern, D. F. (2003). Thought \& knowledge: an introduction to critical thinking (4.Bask1). USA: Lawrence Erlbaum Associates, Inc.

İpşiroğlu, Z. (1993). Türk eğitim sisteminde yaratıcılık. A. Ataman (Ed.). Yaratıcılık ve eğitim XVII. toplantısı. Ankara: Türk Eğitim Derneği Yayınları, No:17. 
Karsantık, Y. (2016). Öğretmen adaylarının düşünme becerilerine ve düşünme becerilerinin ögrretimine yönelik görüşleri. Yayımlanmamış yüksek lisans tezi, Marmara Üniversitesi, İstanbul

Kartal, T. (2012). İlköğretim fen bilgisi öğretmen adaylarının eleştirel düşünme eğilimlerinin incelenmesi. Ahi Evran Üniversitesi Kırşehir Ĕgitim Fakültesi Dergisi, 13(2), 279-297.

Kennedy, M., Fisher, M. B., \& Ennis, R. H. (1991). Critical thinking: Literature review and needed research. In L. Idol, \& B. Fly Jones (Eds.), Educational values and cognitive instruction: Implications for reform (pp. 11-40). Hillsdale, NJ: Lawrence Erlbaum.

Korkmaz, Ö. (2009). Eğitim fakültelerinin öğrencilerin eleştirel düşünme eğilim ve düzeyine etkisi, Türk Eğitim Bilimleri Dergisi, 7(4), 879-902.

Korkmaz, Y., Keleş, Ö. (2014). Beceri temelli eleştirel düşünme eğitiminin ilkokul 3. ve 4. sınıf öğrencilerinin eleştirel düşünme becerilerini geliştirme düzeyine etkisi, ICEMST , 886-894.

Kürüm, D. (2002). Öğretmen adaylarının eleştirel düşünme gücü. Yayımlanmamış yüksek lisans tezi, Anadolu Üniversitesi, Eskişehir.

Levy, D. A. (2010). Tools of critical thinking: Metathoughts for psychology. Long Grove, IL: Waveland Press.

Lipman, M. (1988). Critical thinking-what can it be? Educational Leadership, 46(1), 38-43.

Lipman, M. (2003). Thinking in education. Cambridge: Cambridge University.

McCall, C.C. (2017). Düşünmeyi dönüştürmek. (çev. K. Gülenç ve N. Boyac1). Ankara: Nobel Yayınları. (Orjinal çalışmanın basım tarihi 2009)

McGuinness, C. (2000). ACTS (Activating Children's Thinking Skills). In A methodology for enhancing thinking skills. ESRC TLRP First Programme Conference. November.

McPeck, J. E. (1984). Stalking beasts, but swatting flies: The teaching of critical thinking. Canadian Journal of Education/Revue canadienne de l'education, 9, 28-44.

Merriam, S. B. (2013). Qualitative research: A guide to design and implementation. (çev. S. Turan). Ankara: Nobel yayıncılık.

Milli Eğitim Bakanlığı MEB (2004). Tebliğler Dergisi, 67, s.2563, ss. 734 
G. Çatalbaş ve E, Sarıtaş/ Pamukkale Üniversitesi Ĕ̆itim Fakültesi Dergisi, 54, 328-356, 2022

Miri, B., David, B.C. \& Uri, Z. (2007). Purposely teaching for the promotion of higher order thinking skills: A case of critical thinking. Research in Science Education, 37, 353369.

Narin, N. ve Aybek, B. (2010). İlköğretim ikinci kademe sosyal bilgiler ögretmenlerinin eleştirel düşünme becerilerinin incelenmesi. Çukurova Üniversitesi Sosyal Bilimler Enstitüsü Dergisi, 19(1), 336-350.

Nosich, M. G. (2015). Eleştirel düşünme ve disiplinler arası eleştirel düşünme rehberi (çev. B. Aybek ). Ankara: Anı Yayıncılık.

Özden, B. (2005). Eğitim fakültesi ilköğretim bölümü anabilim dalı programlarının eleştirel düşünme becerilerinin gelişimine etkisi. Yayımlanmamış yüksek lisans tezi, Yıldız Teknik Üniversitesi, İstanbul.

Paul, R.; Binker., A.; Martin, D. Vetrano, C.ve Kreklau, H. (1989). Critical thinking handbook: 6th-9th Grades. A guide for remodeling lesson plans in language arts, Social Studies and Science. Rohnert Park, CA: Foundation for Critical Thinking.

Paul, R., Elder, L. (2013). Kritik düşünce-yaşamınızın ve öğrenmenizin sorumluluğunu üstlenmek için araçlar (çev. E. Aslan, G Sart). Ankara: Nobel Akademik Yayıncılık.

Resnick, L. B. (1987). Education and learning to think. National Academies.Washington, USA.

Ritchie, M.S., Edwards, J. (1996). Creative thinking instruction for aborjinal children. Learning and Instruction, 6(1). 59-75.

Rule, A. C. \& Stefanich, G. P. (2012). Using a thinking skills system to guide discussions during a working conference on students with disabilities pursuing STEM fields. Journal of STEM Education: Innovations and Research, 13(1), 43-54.

Saçlı, F. (2013) Yaratıcı drama eğitiminin aday beden ĕgitimi öğretmenlerinin eleştirel düşünme becerileri ve eleştirel düşünme eğilimleri üzerine etkisi. Yayımlanmamış doktora tezi, Hacettepe Üniversitesi, Ankara.

Schreglmann, S. (2011). Konu temelli eleştirel düşünme ögretiminin öğretmen adaylarının akademik başart, eleştirel düşünme eğilimine ve düzeyine olan etkisi. Yayımlanmamış yüksek lisans tezi, Çukurova Üniversitesi, Adana. 
Seferoğlu, S. S. \& Akbıyık, C. (2006). Eleştirel düşünme ve öğretimi. Hacettepe Üniversitesi Ĕ̈itim Fakültesi Dergisi, 30(30) 193-200.

Sternberg, R. J. (1985). Teaching critical thinking, part 1: are we making mistakes?. Phi Delta Kapan, 67, 194-198.

Sternberg, R. J., Grigorenko, E. (2000). Teaching thinking for successful Intelligence. Arlington Heights, Il: Skylight.

Thompson, C. (2011). Critical thinking across the curriculum: Process over output. International Journal of Humanities and Social Studies, 1(9), 1-7.

Tok, E. (2008). Düşünme becerileri eğitimi programının okul öncesi ögretmen adaylarının eleştirel, yaratıc düşünme ve problem çözme becerilerine etkisinin incelenmesi. Yayımlanmamış doktora tezi, Marmara Üniversitesi, İstanbul.

Trilling, B. and Fadel, C. (2009). 21st century skills. USA: HP Publishing.

Watson, G., Glaser, M.E. (2010). Watson-Glaser TM II critical thinking appraisal USA: Pearson.

Yin, R. K. (2003). Case study research. design and methods (3rd ed.). Thousand Oaks: Sage. 


\title{
The Impact of the Implementation of a Skill-Based Thinking Program on the Critical Thinking Skills and Dispositions of Pre-service Classroom Teachers*
}

\author{
Gülsüm ÇATALBAŞ**, Emel SARITAŞ***
}

• Received: 16.07.2021 • Accepted: 27.09.2021 • Online First: 28.09.2021

\begin{abstract}
This research aims to investigate the effect of the CoRT 5 thinking program on the critical thinking skills and dispositions of pre-service classroom teachers. The research was designed as a case study. A 10-week CoRT 5 thinking program was administered to 21 pre-service classroom teachers who formed the research study group. Data collection tools consist of participant and researcher diaries, observation notes, and semi-structured interviews. The thematic analysis method was used for data analysis. Results denoted that there were indicators of critical thinking in the thinking problems encountered during the implementation of the CoRT 5 thinking program and solutions to these problems and in the learning outcomes of the CoRT 5 thinking program. Further, it was observed that the implementation of the CoRT 5 thinking program contributed to the development of preservice classroom teachers' critical thinking skills and dispositions. The pre-service classroom teachers reported that a skill-based critical thinking teaching approach would be more effective.
\end{abstract}

Keywords: critical thinking, skill-based critical thinking, CoRT thinking program, pre-service classroom teachers

\section{Cited:}

Çatalbaş, G. \& Sarıtaş, E. (2022).The impact of the implementation of a skill-based thinking program on the critical thinking skills and dispositions of pre-service classroom teachers. Pamukkale University Journal of Education, 54, 328-356.doi:10.9779.pauefd.972466

\footnotetext{
* This article was produced from the Ph.D. dissertation completed by the first author under the supervision of the second author.

** Dr. Pamukkale University, Faculty of Education, Department of Curriculum and Instruction, , Turkey, https://orcid.org/0000-0001-6971-1079, catalbas@ @au.edu.tr

*** Asst. Prof. Dr.,Pamukkale University, Faculty of Education, Department of Primary Education, , Denizli, Turkey, , https://orcid.org/0000-0000-0002-0101-4987, esaritas@pau.edu.tr
} 


\section{Introduction}

Social structural changes and developments in the 21st century, in which science and technology are advancing rapidly, urged individuals to change their information-seeking and thinking behaviors. For a qualified society, individuals need to develop their thinking systematically, be aware of their thinking skills and have the skills to use them. Lipman (2003) defined thinking skills as the greatest cognitive power of humanity and mentioned four major varieties of thinking skills: inquiry skills, reasoning skills, informationorganizing skills, and translation skills. According to Mcguinness, it became increasingly clear that developing children's thinking goes far beyond an understanding of how children learn, and thinking skills include searching out the order and imposing meaning on information, critical thinking, creative thinking, problem-solving, planning, and making decisions. Fisher (1995), on the other hand, divides thinking skills into three types: critical thinking, creative thinking, and problem-solving skills as the practice of these two skills. Among the 21st learning and innovation skills, critical thinking, creativity, and problemsolving are recognized as sub-skills (Larson, Miller, 2011; Trilling \& Fadel, 2009).

Looking at thinking skills and the place of these skills in curricula, it is seen that the most commonly emphasized and highlighted skill is critical thinking skills. With the changes in thinking processes and in the way we think, individuals' thinking processes have gained importance, and the efforts have been made to increase not only the quantity but also the quality of thinking whereby this has led us to focus on critical thinking (Gündoğdu, 2009; Fisher, 2001 and Schafersman, 1991). According to Doğanay (2000), Facione (2013), and Gürkaynak, Üstel, \& Gürgöz (2008), democratic society requires students to think critically, and that makes critical thinking even more important.

When examining the vast literature on critical thinking, it is observed that there are differences in the definitions of critical thinking, classifications related to the dimensions of critical thinking, and approaches to teaching critical thinking skills. This might be because each discipline adopts a different approach in line with their research areas. According to the philosophical perspective on critical thinking, the nature and systematics o critical thinking are primarily based on philosophical thinking and critical thinker characteristics. The philosophical point of view of critical thinking dates back to Socrates's claim that the unexamined life is not worth living (Gross, 2006, p.49), taking questioning as a basis. As both a philosopher and a psychologist, Dewey (1991) defines reflective thinking as "active, 
persistent and careful consideration of any belief or supposed form of knowledge in the light of the grounds that support it, and the further conclusions to which it tends." (p. 6) and describe reflection as a process involving uncertainty and questioning. This process refers to the concept of critical thinking. Philosopher Lipman (1988), the founder of "Philosophy for Children", asserts that critical thinking relies upon criteria, is self-correcting, and is sensitive to context. For Ennis (1985a), critical thinking is "reasonable reflective thinking that is focused on deciding what to believe and do" (p. 45).

In psychology, critical thinking mostly refers to processes with the question of "how thought can arise?" Paul and Elder (2013), who discuss critical thinking within the discipline of psychology apart from philosophy, draw attention to the meta-cognitive process by defining critical thinking as an art of thinking about thinking. Halpern (1998), Levy (2010), Sternberg (1985), and Watson \& Glaser (2010) associated critical thinking with problemsolving. Cüceloğlu (1994) explains critical thinking as "an active and organized mental process that aims to understand our thinking processes, understand the opinions of others, apply what we have learned, understand ourselves and the events around us" (p. 216). Critical thinking, which is handled with different dimensions in philosophy and psychology, has been examined by educational scientists in the context of four tenets of education programs. While critical thinking is necessary is discussed in the objectives of the curriculum, it is included in the subjects in various courses with its content element. It has been an important area that educators work on in the learning-teaching process, with which approaches and how to teach critical thinking. In the evaluation element, evaluation studies were carried out for critical thinking skills and disposition components.

In considering the differences in the definition of critical thinking, 46 US and Canadian experts from different disciplines were convened to work toward a consensus on the concept of critical thinking within the scope of the Delphi Research Project. American Philosophical Association (APA) claims that critical thinking is "purposeful, self-regulatory judgment which results in interpretation, analysis, evaluation, and inference, as well as an explanation of the evidential, conceptual, methodological, criteriological, or contextual considerations upon which that judgment is based" (Facione, 1990).

To be a good critical thinker, critical thinking skills and dispositions should be considered as a whole (Facione, 1990; Halpern, 2003 and Watson \& Glaser, 2010). Differences in critical thinking are also seen in the classifications for these two components of critical thinking. Beyer (1984) classified the cognitive dimension of critical thinking 
(Ennis, (1985a), Paul, Binker, Martin, Vetrano, \& Krelau (1989), Paul \& Elder (2013), and Watson \&Glaser (2010). In this classification, certain core critical thinking skills were taken into account, and critical thinking skills were classified within the scope of the Delphi Project. Accordingly, critical thinking skills were determined as interpretation, analysis, evaluation, inference, explanation, and self-regulation skills and sub-skills (Facione, 1990). Further, a scale was developed within the scope of the Project.

Researchers who classify critical thinking dispositions (Bailin, Case, Combs, \& Daniels, 1999; Ennis, 1985b; Facione \& Facione, 1996; Fisher, 1995; Halpern, 2003 and Paul \& Elder, 2013) stress that critical thinking skills alone are not enough, there should also be a tendency or willingness to use the skill. Critical thinking dispositions were also classified in the Delphi project. In this context, the dispositions include approaches to living in general and approaches to specific issues, questions or problems. Seven aspects of the overall disposition toward CT were described: truth-seeking, open-mindedness, analyticity, systematicity, self-confidence, inquisitiveness, and maturity (Facione, 2013).

Another major debate revolves around teaching methods to be used to create effective critical thinkers. Kennedy, Fisher, and Ennis (1991) describe four instructional approaches to critical thinking. These approaches are classified as infusion, immersion, general, and mixed approaches. According to researchers (Halpern, 1998; McGuinnes, 2000; McPeck, 1984; Nosich, 2015; Paul \& Elder, 2013; Resnick, 1987), who advocate for subject-focused critical thinking education, that is to say, integrating critical thinking skills into regular academic content, critical thinking cannot be taught with a few hours of courses. Infusing critical thinking skills while teaching the subject may enhance students' interest and motivation. An infusion or immersion approach can be adopted to infuse critical thinking into subject area content. In the infusion approach, the general principles of critical thinking are made explicit to students. In the immersion approach, however, students are immersed in the subject without being specifically referred to the principles of critical thinking (Hager \& Kaye, 1992; Mcguinness, 1999 and Resnick, 1987 ;). Researchers who adopt the approach called skill-based teaching of critical thinking or the general approach (Beyer, 1985; De Bono, 2002; Ennis, 1985b; Fisher, 1995; Lipman, 1988; McCall, 2017) claim that critical thinking can be taught through a separate course or training. Specially designed programs such as "Philosophy for Children" initiated by Lipman (2003), De Bono's Cognitive Research Trust (CoRT) program, and Feuerstein's Instrumental Enrichment program are used for skill-based critical thinking 
teaching. As for the last approach, the mixed approach consists of a skill-based approach combined with either the infusion or immersion approach (Kennedy, Fisher \& Ennis, 1991). The mixed approach is an approach to complement the shortcomings of these three approaches.

It remains debatable which strategy or approach to teaching critical thinking skills. However, it is worth noting that teachers indisputably have an important role in instilling critical thinking in students (Demirel, 2007; Idol, Jones, \& Mayer, 1991; Narin \& Aybek, 2010; Seferoğlu \& Akbıyık, 2006). The Commission on Effective Teachers and Teaching emphasized that students should be trained with 21 st-century skills such as critical thinking, problem-solving and creative thinking to cope with global challenges, and it is important for teachers and pre-service teachers to acquire these skills (Commission on Effective Teachers and Teaching [ CETT], 2011).

The common basic skills aimed to help students gain were included in the Turkish National Education primary science curriculum, which was prepared based on a constructivist approach in 2005. These skills are critical thinking, creative thinking, communication, and research-inquiry, problem-solving, using information technologies, entrepreneurship, and using Turkish correctly, effectively, and properly. To enhance students' critical thinking skills, which are considered as the ability to examine issues with a doubt critically, make reasoned judgments, and make decisions (MEB, Journal of Communiques, 2004, 734), teachers who will guide students to think critically should be well-trained through pre-service training. There is a large body of literature about preservice teachers' critical thinking skills and dispositions (Aybek, 2006; Çetinkaya, 2011; Doğanay, Taş, \& Erden, 2007; Karsantık, 2016; Kartal, 2012; Korkmaz, 2009; Kürüm, 2002; Özden, 2005; Saçl1, 2013; Schreglman, 2011 and Tok, 2008). Given that primary school plays a vital role in student's development and teachers should be trained through pre-service training, this research was carried out with pre-service classroom teachers. In this context, the question arises about how pre-service teachers can effectively acquire critical thinking skills through pre-service training. The teacher training program in the 2016-2017 academic year in which the research took place does not offer a stand-alone course in critical thinking skills. The researcher started with whether critical thinking can be taught more effectively with a skill-based course and associated programs.

Among the skill-based critical thinking teaching programs, the CoRT Thinking program designed by Edward De Bono entails thinking tools for the direct teaching of 
thinking skills systematically. De Bono (2002) stated that all age groups from six years old to adults could be trained to practice his program, and the program, which has six sections, each of which consists of ten lessons, can be easily applied in different areas. CoRT thinking program is extensively applied in many countries such as America, England, Ireland, Canada, Australia, Malta, New Zealand, Italy, Venezuela, Malaysia, Singapore, and South Africa and is included in education programs. While previous studies applying for this program (Al-Edwan, 2011; Aybek, 2006; Barak and Doppelt, 2006; Ritchie \& Edwards, 1996 and Rule \& Stefanick, 2012) demonstrate that the program can be used effectively in different fields, studies conducted in Turkey (Aybek, 2006); Bayrak, 2014; Korkmaz \& Keleş, 2014) remain limited to the implementation of the CoRT 1. The fifth chapter of "Information and Feeling" (CoRT 5) is a section where predictions about thinking activities and solutions are made under the lessons titled information, questions, clues, guesses, beliefs, emotions, values, contradiction, ready-mades, and simplification. For this reason, the CoRT 5 program, which is thought to help develop critical thinking skills, was employed in this study.

This study investigates the impact of the CoRT 5 thinking program on pre-service teachers' critical thinking skills and dispositions. To this end, the following questions were sought to answer: "What are the indicators of critical thinking in pre-service classroom teachers who received the CoRT 5 thinking program training", "What kind of contributions did CoRT 5 thinking program training provide on pre-service classroom teachers' critical thinking skills and dispositions?" and "What are the views of the pre-service classroom teachers on critical thinking instruction?

\section{Methodology}

\section{Research Design}

In this study, a holistic single-case study, one of the qualitative research designs, was employed. According to Meriam (2013), the purpose of the case study is to focus on the phenomenon instead of testing the hypothesis and reveal the interaction of significant factors related to that phenomenon. The holistic single-case design was chosen because the effects of the implementation of the thinking program on pre-service teachers were identified as a case study, and the study attempted to confirm or refute the program's contributions to preservice teachers' critical thinking skills and dispositions. In addition, the absence of studies on the implementation of the CoRT 5 thinking program, including pre-service teachers in the Turkish literature, is considered a unique situation. 


\section{Participants}

The participants included 21 fourth-grade pre-service classroom teachers studying at the Education Faculty of Pamukkale University. Criterion sampling, one of the purposeful sampling methods, was used to determine the study group. In selecting the study group, the fact that the participants have attended the Teaching Practice I course and have not participated in a thinking training program before was considered. The participants consisted of 16 female and five male pre-service classroom teachers. Fifteen of the participants, predominantly public high school and Anatolian high school graduates, chose the teaching profession willingly, whereas six of them chose unwillingly. The majority of the students made their first six choices in department preference in the university entrance examination. Fourteen participants find themselves as critical thinkers at a medium level, two at a good level, and five pre-service teachers at a low level. The majority of the participants mostly use the internet and social media as a source of information to reach up-to-date information.

\section{Data Collection Tools}

In the study, data diversification was made by using more than one qualitative data collection technique. Thus, it was intended to increase the credibility of the research by ensuring that the collected data confirm each other (Merriam, 2013). In this frame, "Personal Information Form", "Participant Diaries", "Researcher Diary", "Video Records of Participant Observation," and "Semi-structured Interviews" were used as data collection tools.

\section{Personal information form}

The personal information form was developed to describe the participants better and to interpret the findings when necessary. The personal information form contains questions based on gender, type of high school graduated, willingness to choose classroom teaching, order of preference in the university exam, grade point average, whether they have received a thinking course or training before, the level they see themselves as a critical thinker, what information sources they use to reach up-to-date information and their frequency of use.

\section{Participant diaries}

In the study, pre-service teachers were asked to think about their daily experiences and keep diaries at the end of each lesson throughout the implementation of the thinking program. A form consisting of a series of questions was created for the participant diaries. In the meantime, the two experienced qualitative researchers in thinking skills were consulted. In 
this form, some questions made them think about the difficulties they encountered in the thinking activities, the solutions, what they learned, and how they could apply what they learned in their daily lives.

\section{Researcher diary}

As the program practitioner, the researcher interacted with the participants, made observations, took notes, and kept her experiences in the research diary.

\section{Participant observation}

Participant observation was adopted as the type of observation in the study. While Yin (2003) defines participant observation as a special mode of observation in which the researcher is not a passive observer, Merriam (2013) explains it as a type of observation in which the researcher usually participates in the role of a participant but does not fully commit himself /herself to the activities. In this study, the researcher assumed the role of the observer as a participant. In order to increase the validity of the data collected by participant observation, video camera recording was used in the research.

\section{Semi-structured interviews}

Individual interviews were conducted using a semi-structured interview form in two weeks after completing the thinking program. The interview form was finalized by taking the opinions of two faculty members who are specialized in qualitative research and thinking skills instruction. The participants were asked how their education made them think critically, the strategies they developed during the thinking activities, whether it made a difference in their thinking structures and their suggestions for critical thinking. The interviews were recorded on the voice recorder with permission from the participants.

\section{Implementation and Data Collection Process}

In this study, firstly, the CoRT 5 thinking program provided was translated from English to Turkish and presented to an English expert and a faculty member studying thinking skills. In line with the feedback received, necessary corrections were made in terms of language and meaning.

The implementation took place in two stages as a pilot and main implementation. After testing the comprehensibility of the CoRT 5 thinking program with the pilot application, the actual application was carried out in the Teaching Practice I course with the fourth-grade teacher candidates studying in the fall semester of the 2016 - 2017 academic 
year. It was stated as the limitation of the research that it was not possible to carry out the application in an independent course following the basic understanding advocated in skillbased thinking education at the time the research was conducted. The thinking program application was carried out in the two-hour theoretical part of the Teaching Practice I course to allow the participants to observe their critical thinking skills in primary schools, evaluate their own critical thinking skills, and think as a teacher. The research lasted 14 weeks.

In the first week of the application, the purpose and process of the research were explained. Afterward, a ten-week program was implemented. The first lesson of the program is the Information lesson, and the obvious information about a given situation and the missing information was determined, and the situation was tried to be clarified. The second lesson is the questions lesson. Attention was drawn to the importance of asking questions to obtain information with fisherman and hunter questions. In the third lesson, in which there was a Clues lesson, activities to find clues were carried out as important parts in accessing information and solving problems. In the fourth lesson, the distinction between contradictions and false conclusions was made, while in the fifth lesson, quessing studies were carried out. The sixth lesson is the lesson of beliefs. In this course, reflection studies were carried out on whether the beliefs held by the person are his personal beliefs or the beliefs formed by others. The source of ideas was also examined in the ideas course following the beliefs course. Aiming to draw attention to the importance of emotions in thinking, thinking activities on ordinary and egoic emotions were carried out in the emotions course. The role of values in the thinking process of the ninth lesson is a test that aims to make students aware of values. The last lesson was a simplification lesson, which included activities to make the information seen as complex simpler and clearer. Observation records, diaries, and data were collected during the implementation process. In the 12th week, a semi-structured interview schedule was determined, and these interviews were held in the last two weeks.

\section{Data Analysis}

In this study, thematic analysis was employed for data analysis. Braun and Clarke (2006) define thematic analysis as "a method for identifying, analyzing and reporting patterns within data." (p.79). The six steps of thematic analysis is shown in Figure 1. 

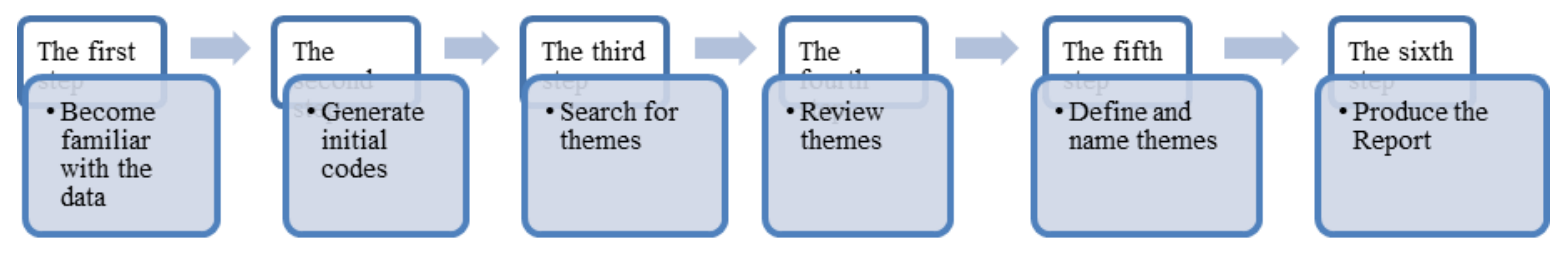

Figure 1. Phases of thematic analysis

The researcher recorded the first data analysis stage in her diary as "familiarizing with the data." After the first reading of the textual data in the computer environment, it was read and re-read to get a sense of what the data says. In other words, it was tried to re-familiarize with the data. In the second stage, the entire data set was systematically reviewed and coded according to the prominent features, and similar data were grouped under a category and coded at the end of the readings. In the third stage, the codes obtained from the data were gathered under a theme in line with the common features. In the fourth stage, where the themes were reviewed, the emerging themes and the relevant data were re-read and reviewed, and different themes were combined. Then, the themes were defined and named in line with the literature and the participants' statements. During the final stage, the findings were interpreted by picking out some of the quotations, and they were discussed and reported in the context of the literature.

\section{Findings}

Five main themes were identified following the qualitative data analysis to seek answers to the research questions. These themes are thinking problems encountered during the implementation of the CoRT 5 thinking program, solutions to these problems, learning outcomes of the CoRT 5 thinking program, the contributions of the CoRT 5 thinking program to critical thinking skills and dispositions and views on critical thinking instruction. While discussing major findings obtained from main themes, the themes related to critical thinking, which are the main focus of the research, were presented with direct quotations along with the sub-themes implying skills and dispositions.

\section{Indicators of Critical Thinking in the CoRT 5 Thinking Program}

The data were analyzed to seek to answer the first research question, "What are the indicators of critical thinking in pre-service classroom teachers who received the CoRT 5 thinking program training?" After the data analysis, the following main themes were identified: "Thinking problems encountered during the implementation of the CoRT 5 thinking program", "Solutions to thinking problems", "Learning outcomes of the CoRT 5 thinking program," and indicators of critical thinking were examined. 


\section{Thinking problems encountered during the implementation of the CoRT 5 thinking program}

In the study, it was found that the participants encountered thinking problems during the implementation of the skill-based thinking program. These thinking problems were divided into the following sub-themes: critical thinking problems, thinking problems arising from the skill-based program, and physical and emotional problems.

Thinking problems that the pre-service teachers encountered during thinking activities were gathered under the theme of "critical thinking problems." Under this theme, sub-themes were detected: inability to clarify information, inability to ask qualifying questions, narrow thinking, inability to notice contradictions, and intellectual laziness.

The most frequently emphasized problem by the pre-service teachers included the inability to clarify information and ask qualifying questions. The pre-service teachers had problems searching and clarifying the information regarding the given situation and asking questions, and they recorded these problems in their diaries. For instance, Kübra C. experienced problems with clarifying information and reflected her feelings in the diary in the first week as follows: "Our teacher gave us examples. We found the information and skipped information in these examples. I had difficulties in finding the skipped information in some questions". (Kübra 1st diary, 05.10.2016) Akile, on the other hand, reflected in her diary the difficulty she had in asking fisherman questions that led to research and discovery as "The information about the man was incomplete, and I could not find any questions to obtain information" (Akile, second diary, 19.10.2016). Further, Fatih and Kübra experienced problems asking questions and linked it to the traditional education system and upbringing.

In the sub-theme of narrow thinking related to the inability to think from different perspectives, the most frequently highlighted issue by the pre-service teachers is prejudice. In particular, participants linked being stuck on a single clue in the clue lesson to prejudices. For example, Akile shared her thoughts in the semi-structured interview as follows: "In the example of the man who has an office in the skyscraper, we always stuck with the receptionist even though we wrote down all the clues separately. We always thought about the possibility that the man was having an affair with the woman. In this sense, other possibilities have weakened because prejudice has arisen (Akile, Interview, 03.01.2017). On the other hand, Gizem emphasized egocentrism, stating that "If what I am thinking about right now feels right to me, then it is right for me. Theirs only make sense to me, but I accept my truth." As for the researcher, she recorded her observation in her diary in the 2nd week 
as follows: "Do they rely on their thinking structures and themselves too much, or is this a product of self-centered thinking? I will observe this situation a little more. It is still too early." (Researcher, 2nd-week diary, 19.10.2016).

The participants stated that they found thinking and questioning difficult during the implementation process and explained it using the terms such as being easy-going and insensitive. The thinking problems faced by the participants were discussed under the subtheme of intellectual laziness. In this frame, some pre-service teachers stated that they suffered from intellectual laziness. For instance, Ülker said, "I can be too insensitive according to the issue." Hüseyin commented, "I just get stuck on a situation or a clue, I do not care about the other sides of the event, or I want to ignore it" (Hüseyin, third-week diary, 02.11.2016).

\section{Solutions to thinking problems}

In the research, the solutions found by the participants to the thinking problems they encountered during the implementation of the skill-based thinking program were discussed under the main theme of "solutions to the thinking problems". This key theme was divided into two sub-themes: bounding with experiences and solutions to critical thinking. Since the participants attempted to find solutions to thinking problems they encountered in the activities using their own life experiences, finding easier solutions by establishing a relationship between events and real-life situations, the theme of bounding with experiences emerged.

Among the solutions found by the participants to the thinking problems they encountered during the implementation of the skill-based program, the solutions implying indicators of critical thinking were collected under the sub-themes of " interacting with others," "generating alternative ideas," and "empathizing."

The sub-theme of interacting with others was obtained from the data indicating that the participants communicated with their friends to solve the problems they encountered in the given activities, and they cared about the ideas of others while producing solutions. Dilek mentioned that she interacted with others to reach a common consensus and said, "He/she presented his/her idea, I presented my idea. So we both put our ideas together and decided which one made more sense. Yes, you are right; your opinion can solve this situation or mine is the same" (Dilek, Interview, 03.01.2017). Regarding the sub-theme of generating alternative ideas, the participants tried to make inferences by generating alternative ideas to solve the thinking problems they encountered in the thinking activities. 
For example, in the semi-structured interview, Yusuf stated as follows: "First we looked at what we had. We thought about what could happen. After that, we added something ourselves. Then, we thought about the possible ones that we added. This is according to the estimates we have. After that, we reached the result" (Yusuf Interview, 02.01.2017). Empathizing is one of the solutions found by the participants to overcome their thinking problems. The participants especially solved the thinking problems they encountered in the activities in the emotions lesson in the eighth week by empathizing. Merve is one of the preservice teachers using empathy to create solutions. In the semi-structured interview, Merve associated her solution with the activity in the emotions week and said, "Yes, it is from my point of view, but how is it from the perspective of the person in front of me? How is it from the perspective of the person in front of us? I thought I had to think about it from his/her perspective" (Merve, Interview, 03.01.2017)

\section{Learning outcomes of the CoRT 5 thinking program}

As a result of the analysis regarding the achievements of implementing a skill-based thinking program, the main theme of learning outcomes of the CoRT 5 thinking program was identified. Under this theme, the findings of raising awareness on social issues through the thinking activities implemented in the program were collected under one theme. Further, learning outcomes of critical thinking were formed under a different theme.

Under the theme of critical thinking learning outcomes, the sub-themes of clarifying information, asking questions, identifying assumptions, inferring, noticing contradictions, intellectual courage, critical thinking awareness, and understanding of the relationship between emotion and thought were identified. Findings obtained from these sub-themes were considered as indicators implying the cognitive and affective dimensions of critical thinking.

The pre-service teachers encountered thinking problems in courses related to searching for information and clarifying information. The data obtained regarding the preservice teachers' achievements for searching and clarifying information were analyzed under the learning outcome of clarifying information. Meryem remarked the following comment in the first week's diary: "While searching for solutions to the problems in the activities, I tried to reach the information that was not given about the problem. I thought about what could be under the information that was not given" (Meryem, first-week diary, 05.10.2016). Asking qualifying questions is a theme derived from the data related to the experiences in the information, questions, and clues. For Seda, asking questions is the achievement of the 
G, Çatalbaş \& E. Sarıtaş / Pamukkale University Journal of Education, 54, 328-356, 2022

program, and she commented, "For example, I realized that it is more cautious about approaching cases by asking questions... Also, approaching cases by asking questions makes one think even more. That is, it develops thinking skills because every question is asked with the thought" (Seda, 2nd-week diary, 19.10.2016).

The data regarding the outcome of inferring are mainly based on experiences in the clues course in which the detective activity was realized. The pre-service teachers resorted to inductive reasoning by combining the clues and made inferences. For example, Arife expressed the learning outcome of inferring, stating in her diary in the third week as follows: "In today's lesson, we did activities to solve the events through clues. First, we identified the visible clues in the case study in the activity. Then we tried to find other clues. We tried to solve the case by considering the case study in more detail" (Arife, 3rd-week diary, 02.01.2016).

Noticing the contradictions was determined as a learning outcome based on the experiences in the lessons in which thinking activities on contradictory and erroneous inferences frequently encountered in the media and daily life were realized. Seda evaluated her experience both as a thinking problem and as a learning outcome, and she wrote in the 4th-week diary as follows: "For example, one party says it will appoint more teachers as an election promise. I cannot focus on it and not notice the contradictions. However, after this lesson, I learned to think the situation from multiple perspectives and notice the paradoxes and contradictions." (Seda, 3rd-week diary, 16.11.2016).

Intellectual courage and understanding of the relationship between emotion and thought learning outcomes are indicators of critical thinking dispositions. Referring to intellectual courage, Gizem, one of the pre-service teachers, highlighted the disposition to confront as a learning outcome, stating that "Actually, I liked this week's topic because I have taboos about beliefs that I cannot break. In order to question these, we had to question where it came from and how it came to be" (Gizem, 6th-week diary, 30.11.2016). Arife regarded the relationship between emotion and thought as a learning outcome based on the activities in the emotions course, stating that "A successful student who comes to class late ...One day ago, we talked about how we would act on a student who made us angry and came late to the lesson. In the second sentence, we discussed that we may have a prejudice against the student and that we can behave differently. What I learned from this course was about how my emotions led my thoughts." (Arife, 8th-week diary, 14.12.2016). 
To summarize, there are indicators of critical thinking in the thinking problems encountered during the implementation of the CoRT 5 thinking program and solutions to these problems and in the learning outcomes of the CoRT 5 thinking program. In line with these findings, it can be argued that the CoRT 5 thinking program has indicators of critical thinking in response to the first question of the research.

The Contributions of the CoRT 5 Thinking Program to Critical Thinking Skills and Dispositions

The data were analyzed to seek to answer the second research question, "What kind of contributions did CoRT 5 thinking program training provide on pre-service classroom teachers' critical thinking skills and dispositions?" Following the data analysis, the main theme of "The contributions of the CoRT 5 Thinking Program to Critical Thinking" were identified. The main theme was also divided into sub-themes, namely, the contributions of the CoRT 5 Thinking Program to critical thinking skills and the contributions of the CoRT 5 Thinking Program to critical thinking dispositions.

\section{The contributions of the CoRT 5 thinking program to critical thinking skills}

The interview data obtained from the pre-service teachers were analyzed. Accordingly, the contributions of the CoRT thinking program to their thinking structures were divided into the following sub-themes: transferring critical thinking skills, analyzing ideas in depth, and self-regulation. These contributions are related to critical thinking skills. For this reason, it was discussed under the theme of the contributions to critical thinking skills.

According to the participants, the most emphasized contribution of the thinking program is the ability to transfer critical thinking skills. The participants stated that they could use the skills they acquired due to the implementation of the program in the primary school where they practice and in their daily lives. For example, Kübra explained how she incorporated the activities in the information lesson into teaching practice by sharing her experience with a student: "Even our view of the student changes. There was a boy in the internship class that week. He does not listen in any way. So naughty, you know. I asked why like this. I learned that his mother and father are splitting up. I have concluded with the skipped information" (Kübra, Interview, 03.01.2107). Gamze explained how she transferred these skills to daily life, stating that "I mean it was like one level before...I mean, I was listening. I do not go into questioning too much; I do not judge like that, I do not think you 
know. Nevertheless, then I read the news. There is a subtitle. I try to understand if the content fits the news or if there is a contradiction"(Gamze, Interview, 04.01.2017).

Another contribution of the program to critical thinking skills is related to analytical skills. In this sense, the researcher gave the students a news story at the end of the program and observed the process. Afterward, the researcher wrote in her diary: "When I presented the news to the class (for the first time), Merve stated that our country should not accept these immigrants, but then she handled it differently at the end of the implementation. She explained by asking what she did not know in the same news, the positive and negative aspects for the state what the humanitarian effects are" (Researcher, diary, 04.01.2017 2017).

While the participants shared their views on the cognitive activities of the CoRT 5 thinking program, they sometimes evaluated their thinking processes. These findings were considered as a contribution to self-regulation skills. Gizem stated, "Yes. It increased my questioning skills a lot. I usually think on the way home after the internship, you know. This is what should happen, but why can't I do this?" (Gizem, Interview, 03.01.2017). Gizem also added in the interview that she was aware of the over-generalization, pessimism, and irrational beliefs in her thinking structure and tried to correct this situation.

\section{The contributions of the CoRT 5 thinking program to critical thinking dispositions}

The pre-service teachers also commented that the CoRT 5 thinking program contributed to their critical thinking dispositions, which formed the affective dimension of the critical thinking process. Their views were collected under the theme of the contributions to critical thinking dispositions. In this context, the participants stated that the program contributed to critical thinking awareness, open-mindedness, systematicity, willingness to self-correction, and self-confidence in critical thinking.

Among the contributions of the CoRT 5 thinking program to critical thinking dispositions, the most emphasized contribution by the participants is that it increases critical thinking awareness. For example, Dilek explained the contribution of the CoRT 5 thinking program to critical thinking awareness by associating it with the achievements in the ideas course. Dilek articulated that to be a critical thinker, it is necessary to know the source of the ideas, and she explained the program's contribution as follows: "it created awareness in the lessons. I said that is what I think, but did I think of it myself, or did I think like this because of my parents? I questioned myself. How can I be critical without knowing the source of my 
thought? That is how the program worked for me." (Dilek, Interview, 03.01.2017). In the semi-structured interview, on the other hand, Merve commented that she realized that she was prejudiced against events, which was the program's contribution. She also said, "I was more prejudiced towards everything, every situation, people and so on. However, (now) that there may be different reasons behind an action or something said by the other person, or that he/she may act like this from something different from what I think, there must be a reason. I realized that in training"(Merve, Interview, 03.01.2017). Akile, on the other hand, stated that this program improves awareness but does not completely change the thinking structure.

Concerning the theme of open-mindedness, the participants highlighted the program's contributions to affective skills in the sub-dimensions of understanding and listening to others, empathizing, respecting different opinions, thinking from a different perspective, and being objective. Hüseyin, who defines himself as a strict person in his opinions, remarked that he knows how hard it is to change the thinking structure. Referring to the program's contribution in terms of being open-minded, he said, "Teacher, I am a strict guy in my opinions. You know, after this training, I did not change my thoughts directly like that. My rigidity remained, but I softened myself a little more. I started to consider the opinions of others" (Hüseyin, Interview, 27.12.2016)

It was observed that the participants tried to follow a planned and careful working process in the phase of reasoning while questioning the situations given in the thinking activities. The data obtained are discussed in the sub-theme of systematicity as a contribution of the CoRT 5 thinking program. In the interview, Merve reported that the program contributed to the organizing thinking disposition and said, "I have to criticize, but how can I do it? I understood this better after these training... We did not know just how things that we knew were done. We have to do this, but I never knew how to do it". (Merve, Interview, 03.01.2017).

The participants reviewed their thinking structures through the thinking activities in the implementation process; they accepted their mistakes in the thinking processes and showed a tendency to learn from these mistakes. Findings were discussed in the sub-theme of willingness to self-correction. Kübra, one of the participants, explained this contribution with canvas and colors in her interview as follows:

This thinking training has become one of the most beautiful colors on my life canvas. It was like until now. Because I always wanted to see their negativities, it was as if 

is a more colorful brush. Moreover, there is a silhouette there. Furthermore, that silhouette became my silhouette (Kübra, Interview, 03.01.2017).

While only one participant reported the program's contribution to self-confidence in critical thinking, two participants argued that the program did not directly contribute to their critical thinking skills and dispositions, and one participant stated that he/she is not aware of its contribution.

\section{The Views of the Pre-service Classroom Teachers on Critical Thinking Instruction}

Following the analysis of semi-structured interviews, which were conducted to answer the third research question, "What are the views of the pre-service classroom teachers on critical thinking education?" the data obtained revealed the main theme of "Views on Critical Thinking Instruction". These views were discussed under the themes of skill-based critical thinking instruction, critical thinking skills integrated with course content, and critical thinking instruction with a mixed approach.

The views of the pre-service teachers that critical thinking should be taught as a separate course independent from all courses were gathered under the theme of skill-based critical thinking instruction. Fourteen pre-service teachers in the research study group reported that thinking education in general and critical thinking education, in particular, should be incorporated into the education faculties' curricula as a skill-based course. For instance, Dilek expressed her views as follows:

I think such an education should be given because we did not think about it until we took this course. I realized it. I mean, we were looking at everything superficially. So, how do we instill this in children while we are doing this? How do we expect children to think so? So we did not even question their inquiries. We accept everything directly. I think such training is necessary (Dilek, Interview, 03.01.2017).

Ülker, on the other hand, said that skill-based critical thinking education should not be limited to education faculties adding that "I even think that it is of great importance not only as an education faculty formation but also in interpersonal relations. It can be introduced as a common course to all departments in the university, like Revolution, English" (Ülker, Interview, 05.01.2017). For Gizem, teachers who continue their profession should also receive this training. She justified it by saying, "Because you can change your thinking first so that you can think properly so that the child can also change their thinking". 
According to the pre-service teachers, critical thinking instruction should be included as one of the compulsory subjects in the primary school curriculum. Arife commented as follows " $I$ think it would be useful to have such a course. In primary schools, it should start from the very basics. I mean, as the twig is bent, so grows the tree. For example, it should be taught in the 1st grade anyway. There should be such a lesson" (Arife, Interview, 04.01.2017). Seda and Gizem pointed out the lack of critical thinking skills in social conflicts stating that acquiring these skills is crucial for society. Seda expressed her opinion in the semistructured interview as follows, "I mean I even wish that there were such critical thinking courses in public training. You know I wish our people could take it, my mothers, etc. You know, I think everyone should go and take it. I do not know because I was very impressed"(Seda, Interview, 02.01.2017).

The pre-service teachers' views stating that critical thinking should be integrated into course content in both teacher training and primary school curricula were examined under the theme of "critical thinking instruction integrated with the course content". Hasret reflected her thoughts, stating that, "I think it is something that should be included in every lesson" (Hasret, Interview, 27.12.2016). In a similar vein, Gökhan said, "For example, there is no need for a separate course, my teacher. So we can use it in all classes. We can add it to the content of all courses. We can apply our methods and techniques accordingly. We can create discussion environments for different thinking skills" (Gökhan, Interview, 03.01.2017). According to the participants, critical thinking skills can be acquired using teaching methods and techniques such as problem-solving, drama, brainstorming, and debate at every lesson level in primary schools with an approach integrated with the course content. For example, Emre said, "Drama in primary schools. It is the first thing that comes to my mind-drama technique. The teacher was reading something to the students from daily events. Asking them to improvise. Alternatively, revealing their thoughts through brainstorming." (Emre, Interview, 03.01.2017).

Four participants, who articulate that critical thinking can be taught more effectively with a mixed approach, agreed on combining a skill-based approach and an integrated approach with the course content. According to the participants, critical thinking can be taught effectively if basic components of critical thinking skills are incorporated into course content, and they are encouraged to practice these skills in other courses. For example, Kader expressed her opinion as follows: "In primary schools, it can be given as separate 
lessons to children. Then we try to integrate it with the lessons."(Kader, Interview, 05.01.2017).

\section{Result and Discussion}

In an attempt to approach the research holistically, the results and data were presented and discussed in light of the research questions. In the first stage, the indicators of critical thinking in the skill-based program were implemented; in the second stage, the contributions to the critical thinking skills and dispositions; and lastly, the findings related to the views on critical thinking instruction were discussed.

During the CoRT 5 thinking program, indicators of critical thinking in thinking problems encountered, solutions to these problems, and learning outcomes were examined. Thinking problems identified as the inability to clarify information, ask qualifying questions, narrow thinking, inability to notice contradictions, and intellectual laziness were regarded as findings indicating critical thinking components. For Nosich (2015), these thinking difficulties refer to the factors hindering the standards of critical thinking, while Paul \& Elder (2013) put forward-thinking illusions to explain these difficulties. On the other hand, Sternberg \& Grigorenko (2000) and Gündoğdu (2009) classified these difficulties as obstacles to critical thinking. The pre-service teachers claimed that the source of the thinking problems they encountered were negative experiences such as prejudices, traditional education, upbringing, inability to focus, being stuck, and self-centered thinking. According to Paul \& Elder (2013), the individual was born into a culture, raised by parents with particular beliefs, and formed associations with people with a viewpoint are the major influences that shape one's thinking process. İpşiroğlu (1993) explained this situation with the metaphor of "canned children," implying that children stuck at an impasse do not ask questions, do not question, and do not think due to the authoritarian education system, traditional and stereotyped education approaches.

The fact that pre-service teachers who faced thinking problems in the activities given during the implementation of the thinking program strived to overcome these difficulties by interacting with their friends, generating alternative ideas, and empathizing implies that they use critical thinking as a resource. Interacting with friends, generating alternatives, and empathizing concerning fair-mindedness are critical thinking indicators included in the classifications of critical thinking dispositions (Bailin et al., 1999; Ennis, 1985 (b); Facione \& Facione 1996; Halpern, 2003 and Paul \& Elder, 2013). The findings regarding the preservice teachers' achievements related to critical thinking were discussed under the theme of 
learning outcomes. In this respect, the learning outcomes involve clarifying information, asking questions, identifying assumptions, inferring, and noticing contradictions, and these are linked to the dimension of critical thinking skills. Learning outcomes expressed as intellectual courage, critical thinking awareness, understanding the relationship between emotion and thought can be associated with critical thinking dispositions. The learning outcomes obtained in the research are included in critical thinking classifications of different researchers in the critical thinking literature (Bailin et al., 1999; Beyer, 1984; Ennis, 1985b; Demirel, 2007; Facione, 1990; Halpern, 2003; Paul et al., 1989; Paul \& Elder, 2013; Watson $\&$ Glaser, 2010). However, among the learning outcomes of the thinking program implemented, no indicator regarding the evaluation dimension (the evaluation about the reliability of information sources, evidence, claims, and opposing views) was found in the literature on the classification of critical thinking skills (Beyer, 1984; Ennis, 1985b; Facione, 1990; Paul et al., 1989 and Watson \& Glaser, 2010). Similar results were also reported in Al-Edwan's (2011) experimental study examining the effects of CoRT 1 and CoRT 2 programs on thinking skills and in Özüberk's (2002) research. The lack of activities for this skill can be explained as a limitation of the program.

Learning outcomes related to the dimension of critical thinking dispositions were examined under the sub-themes of intellectual courage, critical thinking awareness, understanding of the relationship between emotion and thought. Regarding the sub-theme of intellectual courage, Paul and Elder (2013) define pre-service teachers' self-criticism and courage to question their thinking structures as an intellectual trait. Costa (2006) explained critical thinking awareness, which is considered a learning outcome of the program, as an achievement of skill-based programs. Regarding the understanding of the relationship between emotion and thought, the final learning outcome of the skill-based thinking program implying the dimension of critical thinking dispositions, Nosich (2015) emphasized the relationship between emotion and thought, stating that emotions are necessary for critical thinking and that thinking provides data from emotions.

As a result of the findings obtained to answer the second question of the research, it was concluded that the implementation of the skill-based thinking program contributed to the skills and dispositions of the pre-service classroom teachers. The contributions of the CoRT 5 thinking program to the critical thinking skills of pre-service teachers are consistent with the previous studies (Al-Edwan, 2011; Aybek, 2006; Barak \& Doppelt, 2006; Bayrak, 2014; Korkmaz \& Keleş, 2014; Ritchie \& Edwards, 1996; Rule and Stefanick, 2012) In the 
implementation of the thinking skills program conducted by Tok (2008) with pre-school teacher candidates, the views of the education group about the program were examined, and the conclusion that the activities carried out in the lesson improved them positively supports the research finding.

The most frequently mentioned contribution of the skill-based thinking program to critical thinking skills by pre-service teachers is the ability to transfer critical thinking skills to new situations. This result coincides with the findings of the research conducted by Aybek (2006), in which most of the students in skill-based CoRT1 thinking experiment group one stated the importance of critical thinking skills in daily life and the necessity of teaching these skills to each prospective teacher.

The contributions related to the sub-themes of critical thinking awareness, openmindedness, systematicity, willingness to self-correction, and self-confidence in critical thinking were discussed under the theme of contributions to critical thinking dispositions. The research finding of contributing to critical thinking dispositions parallels the finding obtained by Bayrak (2014), indicating that the implementation of the CoRT thinking program for 4th-grade primary school students in Science Lesson increased students' critical thinking dispositions. Increasing awareness about critical thinking was the most reported contribution by pre-service teachers. Researchers who advocate skill-based teaching of critical thinking (Beyer, 1984; De Bono, 2002; Ennis, 1985b; Fisher, 1995; Lipman, 1988; McCall, 2017) argue that these programs develop awareness in terms of teaching how to think.

Finally, the views of the pre-service classroom teachers on critical thinking education were determined in the study. These opinions were analyzed under the themes of skill-based critical thinking education, critical thinking education integrated with the course content, and critical thinking education with a mixed approach.

Pre-service teachers mainly recommend skill-based critical thinking education in both teacher training programs and primary school curricula. Researchers who advocate that critical thinking education should be given with a skill-based approach (Beyer, 1984; De Bono, 2002; Ennis, 1985b; Fisher, 1995; Lipman, 1988; McCall, 2017) claimed this skill could be taught and transferred. According to pre-service teachers, critical thinking education with skill-based programs should be incorporated into pre-service teacher training programs from the first grades. A similar result is also found in a study conducted by Aybek (2006) in which pre-service teachers who received the skill-based thinking education course 
reported that the "Thinking Education" course should be given as a compulsory course and in lower grades in education faculties.

According to some pre-service teachers, critical thinking can be taught more effectively with an approach integrated with the course content. This view supports the result of Han \& Brown's (2013) research that examined the effects of course intervention that integrated critical thinking with the early childhood contents, based on Paul and Elder's framework of critical thinking. The results indicated that early childhood teacher candidates' dispositions toward critical thinking significantly increased after the intervention. In addition, their knowledge about critical thinking and ability to apply critical thinking in their learning showed growth. Some pre-service teachers who suggest an integrated approach think that critical thinking skills can be gained by using different teaching methods and techniques at each lesson level in primary schools. Miri, David, and Uri (2007) concluded that if teachers purposely and persistently practice higher-order thinking strategies, such as dealing with real-world problems, encouraging open-ended class discussions, and fostering inquiry-oriented experiments, there is a good chance for a consequent development of critical thinking capabilities.

Pre-service teachers who expressed their views on the mixed approach, on the other hand, believe that a critical thinking education integrated into other course contents in the curriculum as well as the skill-based course will be more effective. These views are similar to the view that the mixed approach is the most effective tool in teaching the thinking skills of pre-service teachers in Karsantık's (2016) study. Abrami et al. (2008), in their metaanalysis study in which 117 studies were examined, concluded that the indirect approach was the least effective and the mixed approach was the most effective in teaching critical thinking skills.

The results denoted that a 10-week CoRT 5 thinking program can develop critical thinking in primary school pre-service teachers. These results were supported by the indicators of critical thinking skills and dispositions. In this frame, it can be contended that in critical thinking education, CoRT 5 thinking program in particular and skill-based thinking programs, in general, can be used in teacher training. With longitudinal studies, arrangements can be made in the teacher training cycle. Critical thinking education in the context of 21 st-century skill can be provided to all segments of society through formal and non-formal education. Thus, it can be considered as a part of lifelong learning. 
Ethical Approval: This article was produced from the doctoral thesis titled "Critical Thinking Skills and Dispositions of Prospective Classroom Teachers through CoRT 5 Thinking Program" completed in 2018. Since the research data were collected before 2020, there is no ethics committee approval.

Conflict Interest: There is no conflict of interest between the article's authors.

Authors Contributions: The authors have contributed equally to this paper.

\section{Reference}

Abrami, P.C., Bernard, R.M., Borokhovski, E., Wade, A., Surkes, M.A., Tamim, R., \& Zhang, D. (2008). Instructional interventions affecting critical thinking skills and dispositions: A stage 1 meta-analysis. Review of Educational Research, 78(4), 11021134.

Al-Edwan, Z.S. (2011). The effectivenes of a trianing program based on cognitive reserarch trust strategies to develop seventh grade students' critical thinking in history course, Journal of Social Sience,7(3), 436-442.

Aybek, B. (2006). Konu ve beceri temelli eleştirel düşünme öğretiminin öğretmen adaylarının eleştirel düşünme eğilimi ve düzeyine etkisi. Yayımlanmamış doktora tezi, Çukurova Üniversitesi, Adana.

Bailin, S., Case, R., Coombs, J. R. \& Daniels, L. B. (1999). Conceptualizing critical thinking. Journal of Curriculum Studies, 31(3), 285-302.

Barak, M. \& Doppelt, Y. (1999). Integrating the Cognitive Research Trust (CoRT) Programme for creative thinking into a project-based technology curriculum. Research in Science \& Technological Education, 17(2), 139-151.

Bayrak, Ç. (2014). CoRT 1 düşünme programının "yaşamımızdaki elektrik" ünitesinde kullanılmasının ögrencilerin akademik başarılarına, bilimsel yaratıcılıklarına ve eleştirel düşünme eğilimlerine etkisi. Yayınlanmamış yüksek lisans tezi, Adnan Menderes Üniversitesi, Aydın.

Beyer, B. K. (1984). Improving thinking skills: practical approaches. Phi Delta Kappa International, 65, 556-560. 
Beyer. K. B. (1985). Practical strategies for direct instruction in thinking skills. In A.Costa (Ed.). Developing minds Vol 1 (145-150). Alexandria: Virginia.ASCD.

Braun, V. and Clarke, V. (2006). Using thematic analysis in psychology. Qualitative Research in Psychology, 3(2), 77-101.

Case, R. \& Wright, I. (1997). Taking seriously the teaching of critical thinking. Canadian Social Studies, 32(1), 12-19.

Commission of Effective Teachers and Teaching [CETT]. (2011). Transforming teaching: Connecting professional responsibility with student learning. http://www.nea.org/assets/docs/Transformingteaching2012.pdf sayfasindan erişilmiştir.

Costa, Arthur L. (2006). Five themes in thought-full curriculum. Thinking Skills Creativity, $1,62-66$.

Cüceloğlu, D. (1994). İyi düşün doğru karar ver (6. Bask1). İstanbul: Sistem Yayınc1lık.

Çetinkaya, Z. (2011). Türkçe öğretmen adaylarının eleştirel düşünmeye ilişkin görüşlerinin belirlenmesi. Ahi Evran Üniversitesi Ĕ̆itim Fakültesi Dergisi, 12(3), 93-108.

De Bono, E. (2002). CORT thinking lessons CD. Cavendish information product Ltd. 10 Cavendish Road, Oxford OX27TW, Uk.

De Bono, E. (2011). Kendine düşünmeyi öğret (3. Baskı). İstanbul: Remzi Kitapevi.

Demirel, Ö. (2007). Kuramdan uygulamaya ĕgitimde program geliştirme. Ankara: PegemA Yayıncilık.

Dewey, J. (1991). How we think. NewYork: Pomethus Books.

Doğanay, A. (2000). Yaratıcı öğrenme, A. Şimsek, (Ed.), Sinıfta Demokrasi içinde (171210). Ankara: Eğitim-Sen Yayınları.

Doğanay, A. \& Ünal, F. (2006). Eleştirel düşünmenin öğretimi. A. Şimşek (Ed.), İçerik Türlerine Dayalı Öğretim (209-264). Ankara: Nobel Yayınevi

Doğanay, A., Taş, M. A., \& Erden, Ş. (2007). Üniversite öğrencilerinin bir güncel tartışmalı konu bağlamında eleştirel düşünme becerilerinin değerlendirilmesi. Kuram ve Uygulamada Eğitim Yönetimi, 52(52), 511-546.

Ennis, R. H. (1985). A logical basis for measuring critical thinking skills. Educational Leadership, 43(2), 44-48. 
Ennis, R.H. (1985). Goals for a critical thinking curriculum. A.Costa (Ed.), In Developing Minds, Vol 1 (68-71). Alexandria: Virginia.ASCD.

Facione, P. A. (1990). Critical thinking: A statement of expert consensus for purposes of educational assessment and instruction. Research Findings and Recommendations. Prepared for the Committee on Pre-College Philosophy. New York NY: American Philosophical Association.. ERIC Doc. ED 315-423.

Facione, N. C., Facione, P. A. (1996). Externalizing the critical thinking in knowledge development and clinical judgment. Nursing Outlook, 44, 129-136.

Facione, P. A. (2013). Critical thinking: What it is and why it counts. Millbrae, CA: Measured Reasons and the California Academic Press. ISBN 13: 978-1- 891557-071. http://www.insightassessment.com/pdf sayfasından erişilmiştir.

Fisher, R. (1995). Teaching children to think. UK: Stanley Thornes Ltd.

Fisher, R. (2001). Philosophy in primary schools: fostering thinking skills and literacy. Reading, 35(2), 67-73.

Gündoğdu, H. (2009). Eleştirel düşünme ve eleştirel düşünme öğretimine dair bazı yanılgılar. Celal Bayar Üniversitesi Sosyal Bilimler Enstitüsü, 7(1), 57-74.

Gürkaynak, İ.,Üstel, F. ve Gülgöz, S. (2008). Eleştirel düşünme (3. Bask1). İstanbul: Eğitim Reformu Girişimi.

Hager, P. ve Kaye, M. (1992). Critical thinking in teacher education: A process-oriented research agenda. Australian Journal of Teacher Education, 17(2), 26-33.

Hager, P., Sleet, R., Logon, P.\& Hooper, M. (2003). Teaching critical thinking in undergraduate science courses. Science \& Education, (12), 303-313.

Halpern, D. F. (1998). Teaching critical thinking for transfer across domains: Disposition, skills, structure training, and metacognitive monitoring. American Psychologist, 53(4), 449-455.

Halpern, D. F. (2003). Thought \& knowledge: an introduction to critical thinking (4.Bask1). USA: Lawrence Erlbaum Associates, Inc.

İpşiroğlu, Z. (1993). Türk eğitim sisteminde yaratıcılık. A. Ataman (Ed.). Yaratıcılık ve eğitim XVII. toplantısı. Ankara: Türk Eğitim Derneği Yayınları, No:17. 
Karsantık, Y. (2016). Öğretmen adaylarının düşünme becerilerine ve düşünme becerilerinin ögretimine yönelik görüşleri. Yayımlanmamış yüksek lisans tezi, Marmara Üniversitesi, İstanbul

Kartal, T. (2012). İlköğretim fen bilgisi öğretmen adaylarının eleştirel düşünme eğilimlerinin incelenmesi. Ahi Evran Üniversitesi Kırşehir Eğitim Fakültesi Dergisi, 13(2), 279-297.

Kennedy, M., Fisher, M. B., \& Ennis, R. H. (1991). Critical thinking: Literature review and needed research. In L. Idol, \& B. Fly Jones (Eds.), Educational values and cognitive instruction: Implications for reform (pp. 11-40). Hillsdale, NJ: Lawrence Erlbaum.

Korkmaz, Ö. (2009). Eğitim fakültelerinin öğrencilerin eleştirel düşünme eğilim ve düzeyine etkisi, Türk Eğitim Bilimleri Dergisi, 7(4), 879-902.

Korkmaz, Y., Keleş, Ö. (2014). Beceri temelli eleştirel düşünme eğitiminin ilkokul 3. ve 4. sınıf öğrencilerinin eleştirel düşünme becerilerini geliştirme düzeyine etkisi, ICEMST , 886-894.

Kürüm, D. (2002). Öğretmen adaylarının eleştirel düşünme gücü. Yayımlanmamış yüksek lisans tezi, Anadolu Üniversitesi, Eskişehir.

Levy, D. A. (2010). Tools of critical thinking: Metathoughts for psychology. Long Grove, IL: Waveland Press.

Lipman, M. (1988). Critical thinking-what can it be? Educational Leadership, 46(1), 38-43.

Lipman, M. (2003). Thinking in education. Cambridge: Cambridge University.

McCall, C.C. (2017). Düşünmeyi dönüştürmek. (çev. K. Gülenç ve N. Boyacı). Ankara: Nobel Yayınları. (Orjinal çalışmanın basım tarihi 2009)

McGuinness, C. (2000). ACTS (Activating Children's Thinking Skills). In A methodology for enhancing thinking skills. ESRC TLRP First Programme Conference. November.

McPeck, J. E. (1984). Stalking beasts, but swatting flies: The teaching of critical thinking. Canadian Journal of Education/Revue canadienne de l'education, 9, 28-44.

Merriam, S. B. (2013). Qualitative research: A guide to design and implementation. (çev. S. Turan). Ankara: Nobel yayıncılık.

Milli Ĕ̆itim Bakanlı̆̆ı MEB (2004). Tebliğler Dergisi, 67, s.2563, ss. 734 
Miri, B., David, B.C. \& Uri, Z. (2007). Purposely teaching for the promotion of higher order thinking skills: A case of critical thinking. Research in Science Education, 37, 353369.

Narin, N. ve Aybek, B. (2010). İlköğretim ikinci kademe sosyal bilgiler ögretmenlerinin eleştirel düşünme becerilerinin incelenmesi. Çukurova Üniversitesi Sosyal Bilimler Enstitüsü Dergisi, 19(1), 336-350.

Nosich, M. G. (2015). Eleştirel düşünme ve disiplinler arası eleştirel düşünme rehberi (çev. B. Aybek ). Ankara: Anı Yayıncılık.

Özden, B. (2005). Ĕgitim fakültesi ilköğretim bölümü anabilim dalı programlarının eleştirel düşünme becerilerinin gelişimine etkisi. Yayımlanmamış yüksek lisans tezi, Yıldız Teknik Üniversitesi, İstanbul.

Paul, R.; Binker., A.; Martin, D. Vetrano, C.ve Kreklau, H. (1989). Critical thinking handbook: 6th-9th Grades. A guide for remodeling lesson plans in language arts, Social Studies and Science. Rohnert Park, CA: Foundation for Critical Thinking.

Paul, R., Elder, L. (2013). Kritik düşünce-yaşamınızın ve öğrenmenizin sorumluluğunu üstlenmek için araçlar (çev. E. Aslan, G Sart). Ankara: Nobel Akademik Yayıncıllı.

Resnick, L. B. (1987). Education and learning to think. National Academies.Washington, USA.

Ritchie, M.S., Edwards, J. (1996). Creative thinking instruction for aborjinal children. Learning and Instruction, 6(1). 59-75.

Rule, A. C. \& Stefanich, G. P. (2012). Using a thinking skills system to guide discussions during a working conference on students with disabilities pursuing STEM fields. Journal of STEM Education: Innovations and Research, 13(1), 43-54.

Saçlı, F. (2013) Yaratıcı drama eğitiminin aday beden ĕgitimi öğretmenlerinin eleştirel düşünme becerileri ve eleştirel düşünme eğilimleri üzerine etkisi. Yayımlanmamış doktora tezi, Hacettepe Üniversitesi, Ankara.

Schreglmann, S. (2011). Konu temelli eleştirel düşünme öğretiminin öğretmen adaylarının akademik başart, eleştirel düşünme eğilimine ve düzeyine olan etkisi. Yayımlanmamış yüksek lisans tezi, Çukurova Üniversitesi, Adana. 
Seferoğlu, S. S. \& Akbıyık, C. (2006). Eleştirel düşünme ve öğretimi. Hacettepe Üniversitesi Ĕ̈itim Fakültesi Dergisi, 30(30) 193-200.

Sternberg, R. J. (1985). Teaching critical thinking, part 1: are we making mistakes?. Phi Delta Kapan, 67, 194-198.

Sternberg, R. J., Grigorenko, E. (2000). Teaching thinking for successful Intelligence. Arlington Heights, Il: Skylight.

Thompson, C. (2011). Critical thinking across the curriculum: Process over output. International Journal of Humanities and Social Studies, 1(9), 1-7.

Tok, E. (2008). Düşünme becerileri eğitimi programının okul öncesi öğretmen adaylarının eleştirel, yaratıcı düşünme ve problem çözme becerilerine etkisinin incelenmesi. Yayımlanmamış doktora tezi, Marmara Üniversitesi, İstanbul.

Trilling, B. and Fadel, C. (2009). 21st century skills. USA: HP Publishing.

Watson, G., Glaser, M.E. (2010). Watson-Glaser TM II critical thinking appraisal USA: Pearson.

Yin, R. K. (2003). Case study research. design and methods (3rd ed.). Thousand Oaks: Sage. 